Document downloaded from:

http://hdl.handle.net/10251/166063

This paper must be cited as:

Del Campo Huertas, P.; Navarro Villalba, MT.; Shaikh, SK.; Khokhar, MD.; Aljumah, F.; Martínez, C.; Corma Canós, A. (2020). Propene Production by Butene Cracking. Descriptors for Zeolite Catalysts. ACS Catalysis. 10(20):11878-11891.

https://doi.org/10.1021/acscatal.0c02799

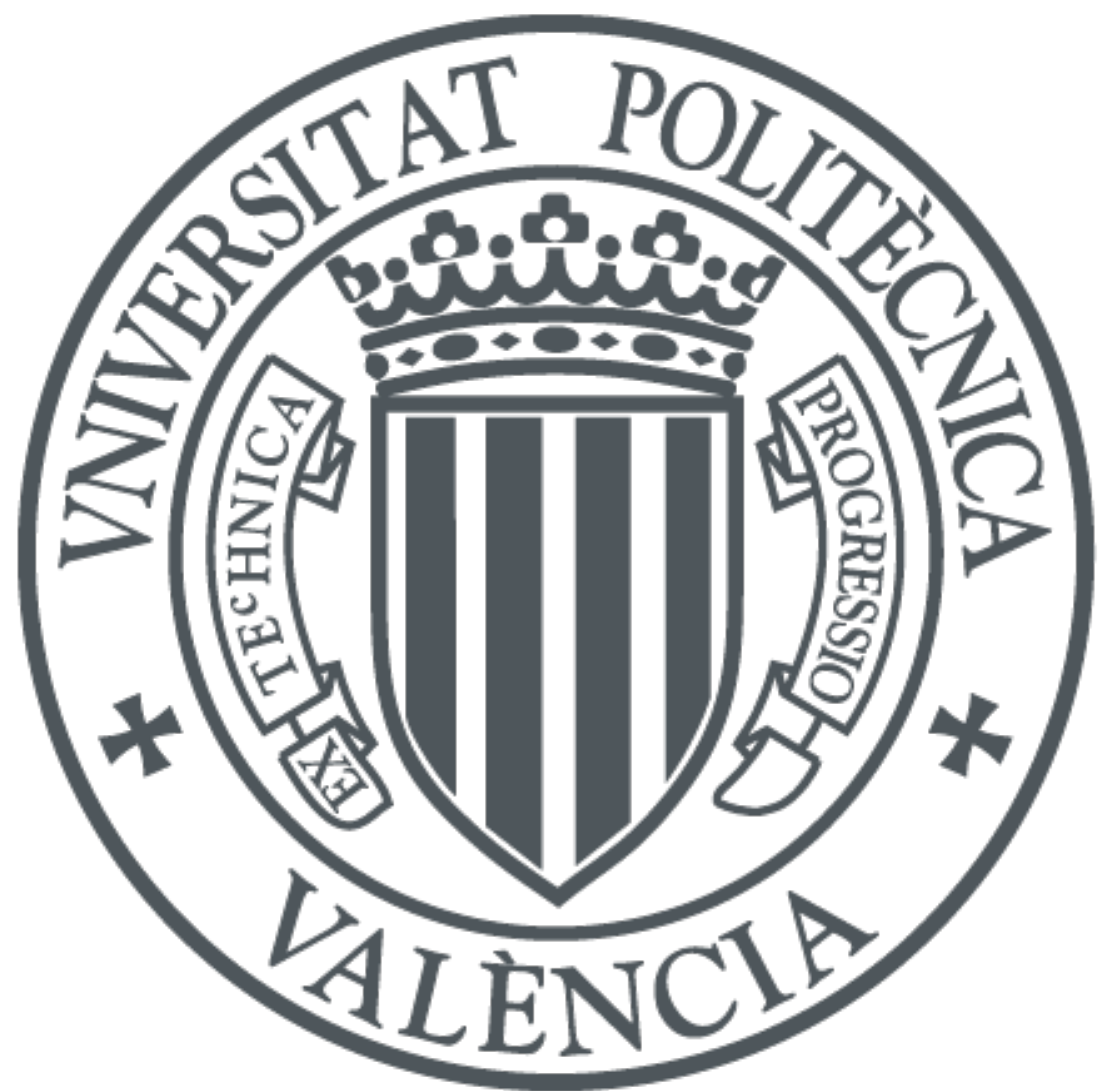

The final publication is available at

https://doi.org/10.1021/acscatal.0c02799

Copyright American Chemical Society

Additional Information

This document is the Accepted Manuscript version of a Published Work that appeared in final form in ACS Catalysis, copyright (C) American Chemical Society after peer review and technical editing by the publisher. To access the final edited and published work see https://doi.org/10.1021/acscatal.0c02799 


\section{Propene production by butene cracking. Descriptors for zeolite catalysts.}

Pablo del Campo ${ }^{1}$, M. Teresa Navarro ${ }^{1}$, Sohel Shaikh ${ }^{2}$, Munir Khokhar ${ }^{2}$, Furqan Jumah², Cristina Martínez ${ }^{1 *}$, Avelino Corma ${ }^{1 *}$

*cmsanche@itq.upv.es (Cristina Martínez), *acorma@itq.upv.es (Avelino Corma)

${ }^{1}$ Instituto de Tecnología Química, Universitat Politècnica de València-Consejo Superior de Investigaciones Científicas, Avenida de los Naranjos s/n, 46022 Valencia, Spain

${ }^{2}$ Research \& Development Center, Saudi Aramco, Dhahran-31311, Kingdom of Saudi Arabia 


\begin{abstract}
Among the possible on-purpose technologies for propene production, direct conversion of butene-rich fractions to propene represents an attractive alternative to conventional routes such as steam cracking or fluid catalytic cracking (FCC). Here we present an approach for designing an efficient ZSM-5 based catalyst for the selective cracking of butenes to propene by properly balancing diffusional and compositional effects. Instead of the large coffin-shaped ZSM-5 crystallites with very high $\mathrm{Si} / \mathrm{Al}$ ratios generally reported, the optimal catalyst in terms of propene selectivity and catalyst life was found to be a ZSM-5 zeolite with squared morphology, sub-micron sized crystals $(0.8 \times 0.3 \mathrm{x}$ $1.0 \mu \mathrm{m}$ ), and $\mathrm{Si} / \mathrm{Al}$ molar ratio around 300 . For this crystal conformation, the short dimensions of both, sinusoidal and straight channels, facilitate propene diffusion and reduce its consumption in consecutive reactions, limiting the formation of $\mathrm{C}_{5+}$ oligomers and aromatics and maximizing propene selectivity. Coffin-type ZSM-5 crystals, with higher diffusional restrictions than square-shaped crystals, show faster catalyst deactivation than the latter, independently of crystal size and Al content. However, among the ZSM-5 zeolite crystallites with coffin morphology, the one presenting intergrowths on the (010) face, with larger proportion of sinusoidal channels, shows lower aromatics selectivity and deactivation rate, whereas the other two, with straight channels open to the clean (010) faces, favour the formation of aromatics by direct cyclisationdehydrogenation of oligomeric intermediates.
\end{abstract}

Keywords: Butene catalytic cracking, propene, ZSM-5 zeolite, crystallite size, morphology, zeolite composition. 


\section{Introduction}

Propene is one of the key building block chemicals in the petrochemical industry, mainly used in the production of plastics and chemicals. Its global production exceeds $100 \mathrm{Mt} / \mathrm{yr}$ since 2017 and its demand is forecasted to be over $150 \mathrm{Mt} / \mathrm{yr}$ in $2050^{1}$.

Propene is mainly produced as a by-product in ethene and fuel manufacture by steam cracking of naphtha and fluid catalytic cracking (FCC), respectively. The yield of propene produced depends on the specific refinery product slate and the operation severity of the process. Purification of propene and ethene derived from the classical processes accounts for $0.3 \%$ of the global energy use ${ }^{2}$, and new materials and selective adsorption processes for separation of ethene and propene are intensively researched ${ }^{3-6}$. Furthermore, the volumes of propene produced by thermal and catalytic cracking have been substantially reduced in recent years due to the emergence of shale gas, as the shift to lighter feedstocks increases ethene production at the expense of propene make. To address this shortfall, several on-purpose routes to propene are gaining interest, such as propane dehydrogenation, ethene-to-propene, methanol-to-olefins (MTO), or olefin metathesis of low value butene fractions coming from $\mathrm{FCC}$ and thermal cracking ${ }^{7,8}$. The upgrade of $\mathrm{C}_{4+}$ olefinic streams by catalytic cracking also represents an interesting option to increase the propene production. It has been integrated into technologies comprising a multi-stage catalyst system, for instance, the UOP/Total petrochemical olefin process, which integrates a cracking step with the MTO process to convert by-product $\mathrm{C}_{4+}$ alkenes into ethene and propene ${ }^{9}$, or the metathesis of butenes combined with the cracking of the $\mathrm{C}_{4+}$ by-products in a second $\operatorname{step}^{7,10-13}$. In addition to the previous approaches, direct conversion of a butenes-rich fraction to propene by catalytic cracking in the presence of a highly selective catalyst, stable towards deactivation, represents an attractive alternative. 
In recent years, there has been an increasing research effort in the production of propene by catalytic cracking of linear butenes on acid zeolite catalysts and ZSM-5, with 10-ring medium pores (MFI), standing out as the main zeolite studied. According to the butenes cracking mechanism ${ }^{14-16}$, high yields of propene could be obtained by dimerization of butenes and selective cracking of the octyl carbenium intermediates to propene and pentenes, provided that other bimolecular reactions, such as hydride transfer, cyclisation and aromatization, are restricted. Recent research has been focused on the benefits of modified ZSM-5 catalyst ${ }^{17}$ or zeolite structures other than $\mathrm{MFI}^{18}$. As compared to ZSM5, large pore zeolites such as mordenite, beta or Y present higher initial activity due to enhanced diffusion of reactants and products, but suffer from fast deactivation due to the promotion of undesired hydride transfer and aromatization reactions leading to coke formation $^{19}$. Zeotype structures presenting cavities, such as the CHA structure of SAPO34 , with large internal cavities connected by narrow 8 -ring apertures ${ }^{20}$, exhibit high initial propene selectivity as compared to a ZSM-5 zeolite, but limited diffusion of reactants and aromatic products results in low catalytic activity and faster coking rates. MCM-22 zeolite, with two independent pore systems, one formed by large supercages accessible through 10-ring windows, and a second one formed by a 2D sinusoidal 10-ring channel system $(4.1 \times 5.1 \AA)$, presents similar propene selectivity as high silica ZSM-5, but lower activity and stability at long reaction time $\mathrm{e}^{21,22}$. One dimensional 10-ring zeolites with TON topology, such as ZSM-22, ZSM-23, ZSM-35 and ZSM-48 ${ }^{20,23}$, hampered hydride transfer and oligomerization reactions because of steric hindrance within their structure, thus leading to good propene selectivity, but pore blocking by coke also led to faster deactivation.

The acidity of the zeolite also plays a crucial role on the performance of the butenes cracking reaction. It is well established that high Brönsted acid site density promotes 
undesired consecutive reactions of hydrogen transfer and aromatization, thus increasing aromatics and paraffins selectivity ${ }^{20,24}$. Higher $\mathrm{Si} / \mathrm{Al}$ ratios and, thus, lower amount of acid sites are preferred for increasing propene selectivity. In this line, ZSM-5 zeolites have been prepared with reduced number of Brönsted acid sites (BAS), either through selective dealumination ${ }^{15,25,26}$ or by incorporating alkali ions within the ZSM-5 lattice ${ }^{27-}$ ${ }^{30}$. Phosphorus incorporation into ZSM- $5^{31}$ was also demonstrated to be an efficient way to reduce hydride transfer activity and to improve propene selectivity ${ }^{15,16,25,28,32-34}$. Furthermore, the phosphorous addition improves the hydrothermal stability of the framework $\mathrm{Al}^{31,32,34}$ and will benefit the catalyst performance upon cycles of catalyst regeneration at the industrial scale. Not only does the acid site density but also the location of these acid sites plays a key role in selective olefin cracking to propene. In fact, recent findings have shown that it is possible to significantly prevent undesired bimolecular reactions in $\mathrm{n}$-hexene cracking by preferential location of $\mathrm{Al}$ in the 10-ring channels, leading to higher propene selectivity ${ }^{35}$.

Increasing the accessible fraction of the zeolite crystal and reducing the diffusional path lengths either by hierarchical pore systems or by adjusting particle size and shape has been also investigated. In particular, the post-synthetic modification of the ZSM-5 by desilication was shown to improve the catalyst stability and light olefin selectivity ${ }^{36}$. The effect of reducing the crystallite size of ZSM-5 helps to ensure stability regarding catalyst deactivation for long-term butenes cracking reactions ${ }^{19}$. Finally, some studies have investigated the effect of catalyst morphology on the cracking activity and selectivity of ZSM-5 based catalysts. Although earlier works comparing ZSM-5 crystals with coffin or rounded-boat morphology but similar size did not give differences in product selectivity for pentene cracking ${ }^{37}$, a recent work with ZSM-5 comprising spherical, sheet-, plate- and noodle-shaped particles showed that the sheet-like crystallites gave the best performance 
for cracking a mixture of $\mathrm{C}_{4 \mathrm{~s}}{ }^{38}$. This was tentatively ascribed to diffusion benefits of the straight pores running along the $b$-axis over the sinusoidal pores along the $a$ axis of the ZSM-5 structure, the former being shorter for the sheet-like morphology.

According to the state-of-the-art, catalysts based on ZSM-5 zeolite with high Si/Al ratios $(>150)$ and large crystal size $(>10 \mu \mathrm{m})$ are believed to be the most adequate in terms of propene selectivity and catalyst life for the butenes cracking reaction ${ }^{10,39,40}$. Although the low amount of Brönsted acid sites leads to low catalyst activity, a larger active site density would increase the number of undesired consecutive reactions within the micropores and, consequently, lead to faster deactivation. While it is true that larger crystallites should lead to a larger number of recracking events, shorter crystallites should improve diffusion and favour catalyst life, provided that unselective reactivity at the external surface is minimized. Moreover, it is shown that other factors such as intergrowth and shape of the crystallites $^{41}$ or preferential orientation of crystals, layers or even membranes ${ }^{42,43}$ can also have an influence on diffusion and, therefore, on reactivity. On that basis, we decided to study here the interplay of diffusional effects, dictated by zeolite crystal size and crystal morphology, with the compositional effect related with Al content, and the objective of maximizing catalyst activity, selectivity to propene and catalyst life. We will present here that it is possible to prepare ZSM-5 samples, out of the conventional range employed for cracking butenes, with a better catalytic behaviour to maximize propene by "butenes cracking". In this way, ZSM-5 samples with very high Si/Al ratios (>200) and sub-micron sized crystallites with square shaped morphology lead to very active catalysts, presenting high yields to propene and high stability towards coke and hydrothermal deactivation, whereas ZSM-5 with coffin-shaped morphology deactivated faster, independently of their crystal size, due to larger diffusional restrictions. 


\section{Experimental}

\subsection{Zeolite synthesis}

2.1.1. ZSM-5 zeolites with different crystallite size and morphology with $\mathrm{Si} / \mathrm{Al} \mathbf{4 0 0}$ prepared in alkaline medium

The first set of samples comprises ZSM-5 zeolites with crystal sizes ranging from 1 to $>$ $10 \mu \mathrm{m}$ and either coffin or square morphology, but similar $\mathrm{Si} / \mathrm{Al}$ ratio in the synthesis gel of ca. 400. Two zeolites with coffin-shaped ( $c f)$ morphology were prepared under alkaline medium. The first one with large crystals $(l, 10-35 \mu \mathrm{m})$ was synthesized adapting the procedure described by Bressel et al ${ }^{44}$ using the colloidal silica suspension Ludox AS-40 as silica source. A second zeolite, with reduced crystal size, was prepared by seeding (intermediate sized, $i, 1.5-3.5 \mu \mathrm{m}$ ). The zeolites with large and intermediate crystal size and coffin morphology were named as MFI4001-cf and MFI400i-cf, respectively. A zeolite composed of crystals of intermediate size $(i, 3-3.5 \mu \mathrm{m})$, but with square-shaped morphology $(s q)$, was synthesized following the same procedure as for MFI4001-cf, but using fumed Aerosil as silica source. This zeolite was coded MFI400i-sq.

A reference ZSM-5 zeolite (MFI2000) with very large crystals (16-60 $\mu \mathrm{m})$, coffin-type morphology and $\mathrm{Si} / \mathrm{Al}$ ratio in the gel of 1000 was prepared under fluoride medium.

Synthesis details of the three methods are given in Table 1 and in the Supporting Information (S1-S2).

\subsubsection{ZSM-5 zeolites with small size crystals and square morphology}

A series of three zeolites with the same crystallite size (small $<1 \mu \mathrm{m}, s$ ), similar morphology (square-shaped tablets, $s q$ ) and increasing $\mathrm{Si} / \mathrm{Al}$ ratios in the gel $(200,400$ and 600) have been prepared. These zeolites were synthesized adding different amounts of $\mathrm{Al}$ to the synthesis gel by adapting a reported procedure ${ }^{45}$. For comparison purposes, a 
pure silica zeolite with the same size and shape was also prepared. The zeolites obtained were coded as MFIxs-sq, where $x$ is the $\mathrm{Si} / \mathrm{Al}$ ratio in the zeolite synthesis gel and $s q$ states for the square-shaped morphology. Synthesis parameters are given in Table 1 and in the Supporting Information (S3).

\section{Table 1}

Synthesis parameters for the ZSM-5 zeolites investigated.

\begin{tabular}{|c|c|c|c|c|c|}
\hline Code & $\begin{array}{l}\text { gel } \\
\text { Si/Al }\end{array}$ & $\begin{array}{l}\mathrm{Si} \\
\text { source }\end{array}$ & OSDA $^{1}$ & $\begin{array}{l}\text { Mine- } \\
\text { ralizer }\end{array}$ & $\begin{array}{l}\text { Gel } \\
\text { composition }\end{array}$ \\
\hline MFI2000 & 1000 & Aerosil & TPABr & $\mathrm{NH}_{4} \mathrm{~F}$ & $\begin{array}{l}1 \mathrm{SiO}_{2}: 0.0005 \mathrm{Al}_{2} \mathrm{O}_{3}: \\
\text { 0.08TPABr: } 0.1 \mathrm{NH}_{4} \mathrm{~F}: 21 \mathrm{H}_{2} \mathrm{O}\end{array}$ \\
\hline MFI4001-cf & 400 & Ludox & TPABr & $\mathrm{NaOH}$ & $\begin{array}{l}1 \mathrm{SiO}_{2}: 0.00125 \mathrm{Al}_{2} \mathrm{O}_{3}: \\
\text { 0.05TPABr: } 0.24 \mathrm{NaOH}: 36 \mathrm{H}_{2} \mathrm{O}\end{array}$ \\
\hline MFI400i-cf ${ }^{2}$ & 400 & Ludox & TPABr & $\mathrm{NaOH}$ & $\begin{array}{l}1 \mathrm{SiO}_{2}: 0.00125 \mathrm{Al}_{2} \mathrm{O}_{3}: \\
\text { 0.05TPABr: } 0.24 \mathrm{NaOH}: 36 \mathrm{H}_{2} \mathrm{O}\end{array}$ \\
\hline MFI400i-sq & 400 & Aerosil & TPABr & $\mathrm{NaOH}$ & $\begin{array}{l}1 \mathrm{SiO}_{2}: 0.00125 \mathrm{Al}_{2} \mathrm{O}_{3}: \\
\text { 0.05TPABr: } 0.24 \mathrm{NaOH}: 36 \mathrm{H}_{2} \mathrm{O}\end{array}$ \\
\hline MFI200s-sq & 200 & TEOS & TPAOH & $\mathrm{NaCl}$ & $\begin{array}{l}1 \mathrm{SiO}_{2}: 0.0025 \mathrm{Al}_{2} \mathrm{O}_{3}: \\
0.2 \mathrm{TPAOH}: 0.005 \mathrm{NaCl}: 70 \mathrm{H}_{2} \mathrm{O}\end{array}$ \\
\hline MFI400s-sq & 400 & TEOS & TPAOH & $\mathrm{NaCl}$ & $\begin{array}{l}1 \mathrm{SiO}_{2}: 0.00125 \mathrm{Al}_{2} \mathrm{O}_{3}: \\
\text { 0.2TPAOH: } 0.005 \mathrm{NaCl}: 70 \mathrm{H}_{2} \mathrm{O}\end{array}$ \\
\hline MFI600s-sq & 600 & TEOS & TPAOH & $\mathrm{NaCl}$ & $\begin{array}{l}1 \mathrm{SiO}_{2}: 0.000625 \mathrm{Al}_{2} \mathrm{O}_{3}: \\
0.2 \mathrm{TPAOH}: 0.005 \mathrm{NaCl}: 70 \mathrm{H}_{2} \mathrm{O}\end{array}$ \\
\hline
\end{tabular}

${ }^{1}$ Organic structure directing agent.

${ }^{2}$ Prepared by addition of 10 wt. \% seeds of MFI600s-sq to the MFI4001-cf synthesis gel.

\subsection{Calcination and ion exchange}

All the as-prepared samples were calcined at $580{ }^{\circ} \mathrm{C}$ for removal of the organic compounds. Then the zeolites were $\mathrm{NH}_{4}{ }^{+}$exchanged to levels of $\mathrm{Na}_{2} \mathrm{O}$ below 0.05 wt. $\%$ using a $2.5 \mathrm{M} \mathrm{NH}_{4} \mathrm{Cl}$ solution at $80^{\circ} \mathrm{C}$ for $2 \mathrm{~h}$ and $1: 10$ solid-to-liquid ratio (wt/wt), and finally calcined in a muffle oven at $500{ }^{\circ} \mathrm{C}$ for $3 \mathrm{~h}$, to obtain the acid zeolite.

\subsection{Catalyst characterization}


The structure and crystallinity of the zeolites was followed by Powder X-Ray Diffraction (PXRD) and the $\mathrm{Si} / \mathrm{Al}$ ratio was determined by Inductively Coupled Plasma (ICP). The size and morphology of the crystals was investigated by means of FESEM. Textural properties were obtained from the nitrogen adsorption isotherms measured at $77 \mathrm{~K}$. Details of the characterization techniques are found in the Supporting Information (S4).

\subsection{Catalytic tests for cracking of butenes}

All the catalytic tests were performed at $550{ }^{\circ} \mathrm{C}$ and atmospheric pressure in a fixed bed continuous reactor system. Before each reaction, the catalyst was activated within the reactor at $550{ }^{\circ} \mathrm{C}$ for $1 \mathrm{~h}$ under $50 \mathrm{~mL} / \mathrm{min}$ nitrogen flow. Then, a mixture of 16 vol.\% 1 butene (99.6 \%, Praxair Spain) in nitrogen was fed to the reactor. The contact time was varied by changing the total flow and/or the amount of catalyst in order to obtain different butene conversions. The reaction outlet was analysed with a Bruker $450 \mathrm{GC}$ Chromatogram equipped with TCD detector, a $\mathrm{BR}-\mathrm{Al}_{2} \mathrm{O}_{3} / \mathrm{Na}_{2} \mathrm{SO}_{4}(50 \mathrm{~m}, 0.53 \mathrm{~mm}$ ID) and a CP-Sil-PONA (50 m, $0.21 \mathrm{~mm}$ ID) capillary columns connected to two FID detectors. Particular aspects of the reaction procedure are given in the Supporting Information (S5).

The butene isomerization rate at $550^{\circ} \mathrm{C}$ in the presence of an acid ZSM-5 catalyst is very fast and the butene isomer distribution rapidly reaches the equilibrium concentrations ${ }^{46}$. Therefore, 1-butene isomerization products have not been considered as reaction products; rather the disappearance of butenes has been considered for determination of the 1-butene conversion. .

\section{Results and discussion}


In this work we have started from the hypothesis that the catalyst descriptors for butene cracking are zeolite composition ( $\mathrm{Si} / \mathrm{Al}$ ratio) and diffusional catalyst factors such as crystal size and crystal morphology. Then, to differentiate the effect of each parameter on activity and selectivity during the cracking of butenes, we have attempted to synthesize zeolite catalysts wherein the above named descriptors were varied one at a time, while maintaining the rest of the catalyst features constant. The objective has been achieved by an adequate synthesis strategy (Section 2.1) and monitored through the characterization results presented below. Finally, the effect of these parameters on the catalytic behaviour of the different ZSM-5 samples for the cracking of butenes will be presented in Section 3.2.

\subsection{Characterization of the ZSM-5 zeolites}

The diffusion of reactant and product molecules to and from the acid sites within the zeolite crystal is controlled by the way in which the microporous channels are interconnected. All the catalysts studied in this work present an MFI topology, as confirmed by the PXRD patterns shown in Figure 1. Then, the channel configuration consists of sinusoidal channels running along the direction of the $a$ axis (intersecting the [100] plane) interconnected with straight channels along the $b$ axis (intersecting the [010] face), and a tortuous and inaccessible path running along the $c$ axis $^{47}$. However, when zeolites are used as heterogeneous catalysts, the diffusion of reactant and product molecules to and from the acid sites within the zeolite crystal is controlled, not only by the pore structure, but also by the morphology and size of the crystallites. In the case of ZSM-5, the diffusional path lengths of the straight and sinusoidal channels and the number of openings to these pores will depend on the size of the crystals along the $a$ and $b$ axis, respectively, whereas the size along $c$ will only affect the amount of channel intersections (see Figure 2). 


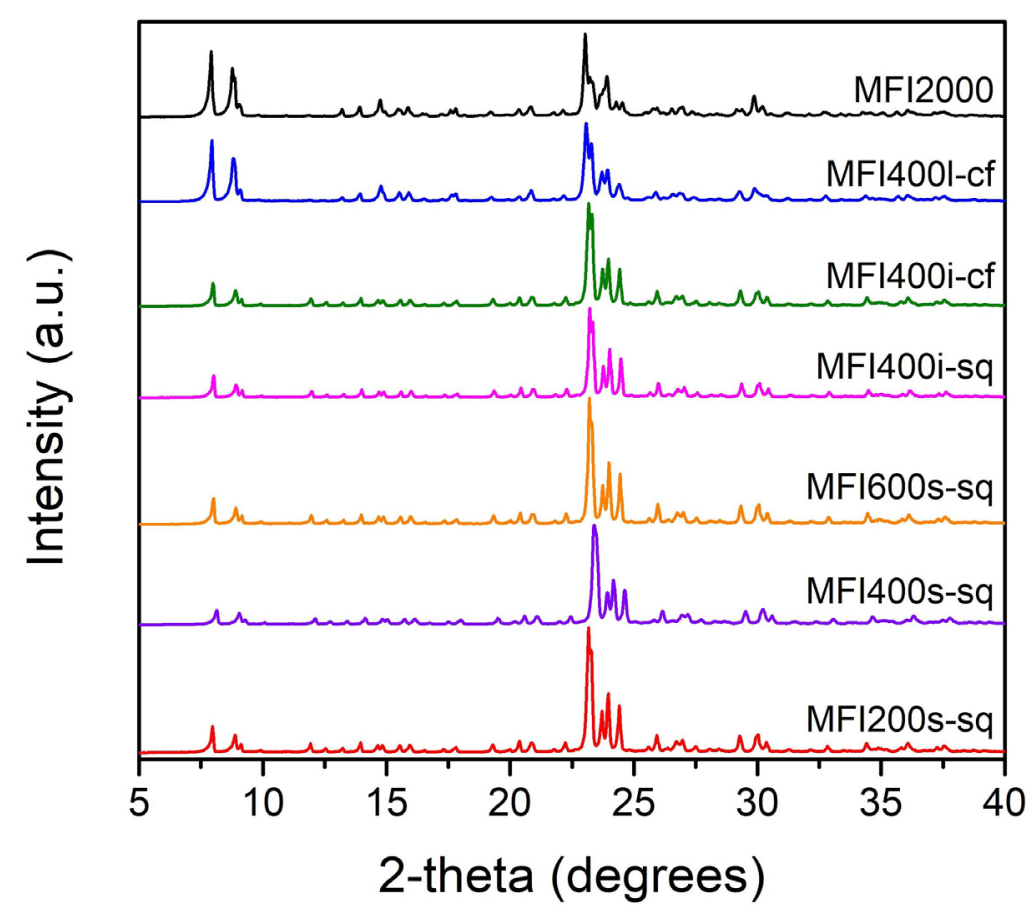

Figure 1. PXRD patterns of the different ZSM-5 zeolites.

Table 2

Properties of the ZSM-5 based catalysts.

\begin{tabular}{|c|c|c|c|c|c|c|c|c|}
\hline$\overline{\text { Code }}$ & $\mathbf{S i} / \mathbf{A} \mathbf{l}^{1}$ & $\begin{array}{c}V_{\text {micro }}{ }^{2} \\
\left(\mathrm{~cm}^{3} \mathrm{~g}^{-1}\right)\end{array}$ & $\begin{array}{c}\text { SBET }^{3} \\
\left(\mathrm{~m}^{2} \mathrm{~g}^{-1}\right)\end{array}$ & $\begin{array}{c}S_{e x t}{ }^{2} \\
\left(m^{2} g^{-1}\right)\end{array}$ & $\begin{array}{l}\text { Crystallite } \\
\text { size }(\mu \mathrm{m})\end{array}$ & $a / c^{4}$ & $a / b^{5}$ & $\begin{array}{l}\text { Crystallite } \\
\text { morphology }\end{array}$ \\
\hline MFI2000 & 786 & 0.16 & 338 & 6 & $16 \times 10 \times 35-60$ & $0.3-0.5$ & 1.6 & coffin \\
\hline MFI400I-cf & 278 & 0.16 & 362 & 8 & $11 \times 6 \times 20-35$ & $0.3-0.6$ & 1.8 & coffin \\
\hline MFI400i-cf & 301 & 0.17 & 386 & 12 & $1.5 \times 0.5 \times 3.5$ & 0.4 & 3.0 & coffin \\
\hline MFI400i-sq & 282 & 0.19 & 398 & 13 & $3 \times 2 \times 3.5$ & 0.9 & 1.5 & square \\
\hline MFI200s-sq & 152 & 0.17 & 433 & 21 & $0.7 \times 0.3 \times 0.8$ & 0.9 & 2.3 & square \\
\hline MFI400s-sq & 289 & 0.16 & 405 & 18 & $0.8 \times 0.3 \times 1$ & 0.8 & 2.7 & square \\
\hline MFI600s-sq & 515 & 0.17 & 424 & 17 & $0.9 \times 0.4 \times 1.1$ & 0.8 & 2.3 & square \\
\hline
\end{tabular}

${ }^{1}$ from the ICP analysis of the acid zeolites.

${ }^{2}$ from the $t$-plot method.

${ }^{3}$ from the BET analysis subjected to the Rouquerol criterion ${ }^{48}$.

4"aspect ratio" defined as $a / c$ dimensions from the ( $a \times b \times c)$ crystallite size values.

5“aspect ratio" defined as $a / b$ dimensions from the $(a \times b \times c)$ crystallite size values. 
Different synthesis methods may lead to MFI zeolites with different crystal shapes and morphologies ${ }^{38,44,45,49-51}$. In line with this approach, we have synthesized ZSM-5 zeolites with different crystal sizes and morphologies, as evidenced by the FESEM images presented in Figure 3. MFI2000 zeolite is composed of coffin-shaped crystals, with sizes of about $16 \times 10 \times 35-60 \mu \mathrm{m}(a \times b \times c)$. Zeolites MFI4001-cf and MFI400i-cf, synthesized with Ludox in alkaline medium, present crystals of $11 \times 6 \times 20-35 \mu \mathrm{m}$ and $1.5 \times 0.5 \times 3.5$ $\mu \mathrm{m}$, respectively, and comparable width- $a$ /length- $c$ ratio ("aspect ratio") as MFI2000 (ca. 0.4). Particularly, MFI4001-cf shows intergrowth structures covering the [010] facet of the main crystal, which are rotated by $90^{\circ}$ with respect to the common crystallographic orientation $^{41,52-54}$. Regarding the main crystal, the pores opened to the zig-zag channels (at the lateral faces) are retained, but the access to the straight channels is largely blocked by the intergrowth subunits. The twined crystal, in turn, exposes mainly the sinusoidal channel mouths at the top face, being the other end of these pores intercepted by the main crystal. This configuration results in a higher proportion of sinusoidal channel pore openings. Zeolite MFI400i-sq has crystals of square-shaped morphology and similar dimensions ( $3 \times 2 \times 3.5 \mu \mathrm{m})$ as compared to MFI400i-cf in the $c$ direction. However, the length along the other two axis ( $a$ and $b$ ) of zeolite MFI400i-sq is double than those of MFI400i-cf, resulting in double the $a / c$ "aspect ratio", from ca. 0.4 to 0.8 , and in longer straight and sinusoidal pores. The shape of MFI400s-sq crystals is similar to that of MFI400i-sq, the former showing a smaller average size of $0.8 \times 0.3 \times 1 \mu \mathrm{m}$. Finally, the three zeolites prepared with different Si/Al ratio (see Table 2), MFI200s-sq, MFI400s-sq and MFI600s-sq, show a homogeneous crystal size distribution of approximately $0.8 \mathrm{x}$ $0.3 \times 1 \mu \mathrm{m}$ and a square-shaped morphology with rounded confronted faces. It is noteworthy that while both coffin- and square-shaped crystals expose [100] and [010] surface orientations, the former present tips at the extremes of the crystals along $c$ 
exposing [101] and [10-1] $\operatorname{surfaces}^{55-59}$, not present in the square-type morphology. These tips were seen to constitute separate segments within the crystals, and the interfaces between the tips and the main crystals could act as diffusion barriers ${ }^{58}$. These discontinuities ascribed to the coffin-shaped crystals may involve diffusional limitations to both, reactants and products.

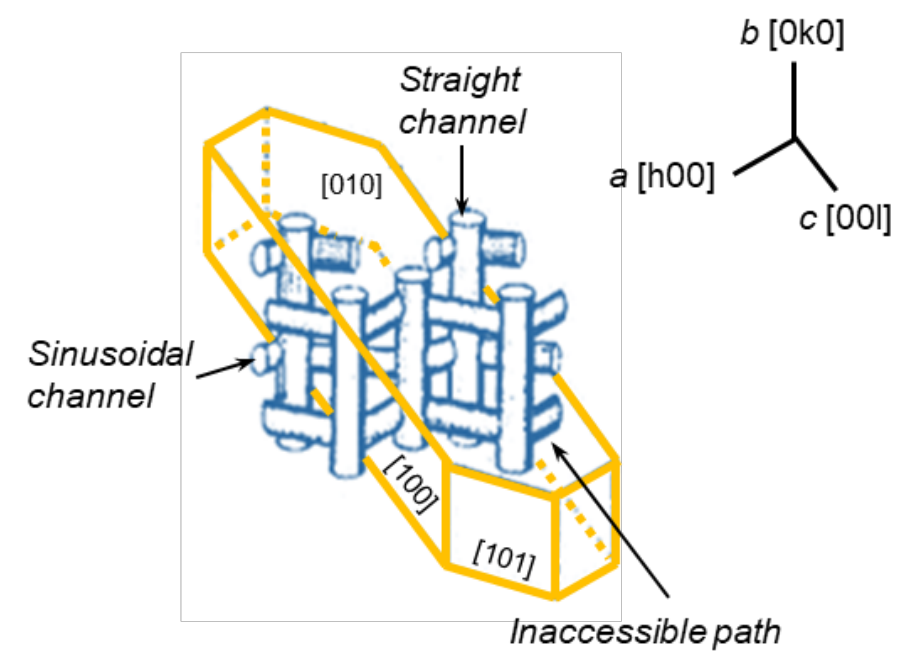

Figure 2. Projections of the channel directions and orientations in a ZSM-5 crystallite (adapted from reference $\left.{ }^{60}\right)$.

The chemical composition and textural properties of the different zeolites are compared in Table 2. The MFI2000 sample has a Si/Al ratio of 786, as expected for this high silica zeolite. The four ZSM-5 synthesized under different conditions but maintaining a Si/Al molar ratio in the synthesis gel of 400, MFI4001-cf, MFI400i-cf, MFI400i-sq and MFI400s-sq, have comparable $\mathrm{Si} / \mathrm{Al}$ ratios in the final solid, close to 300 , and this will allow the study, in an isolated way, of the influence of the crystal size and morphology. The three small-crystal ZSM-5 samples, MFI600s-sq, MFI400s-sq and MFI200s-sq, present $\mathrm{Si} / \mathrm{Al}$ ratios of 515, 289 and 152, respectively. All three zeolites exhibit a total surface area close to $400 \mathrm{~m}^{2} / \mathrm{g}$, a micropore volume of ca. $0.17 \mathrm{~cm}^{3} / \mathrm{g}$, and roughly the 
same external surface area, around $20 \mathrm{~m}^{2} / \mathrm{g}$. The invariance in their textural properties and the high homogeneity of their crystals (igure 3 ) will allows us to assess, in an independent way, the influence of the $\mathrm{Si} / \mathrm{Al}$ ratio for this series on the catalytic cracking of butenes. MFI2000 zeolite shows a slightly lower total surface area of $338 \mathrm{~m}^{2} / \mathrm{g}$ accompanied by the lowest external surface area. As the exposed surface of the zeolites is higher for smaller crystals (MFI400s-sq and MFI400i-cf), their external surface area is higher as compared to their square- and coffin-shaped analogues (MFI400i-sq and MFI4001-cf, respectively) with larger crystals. 

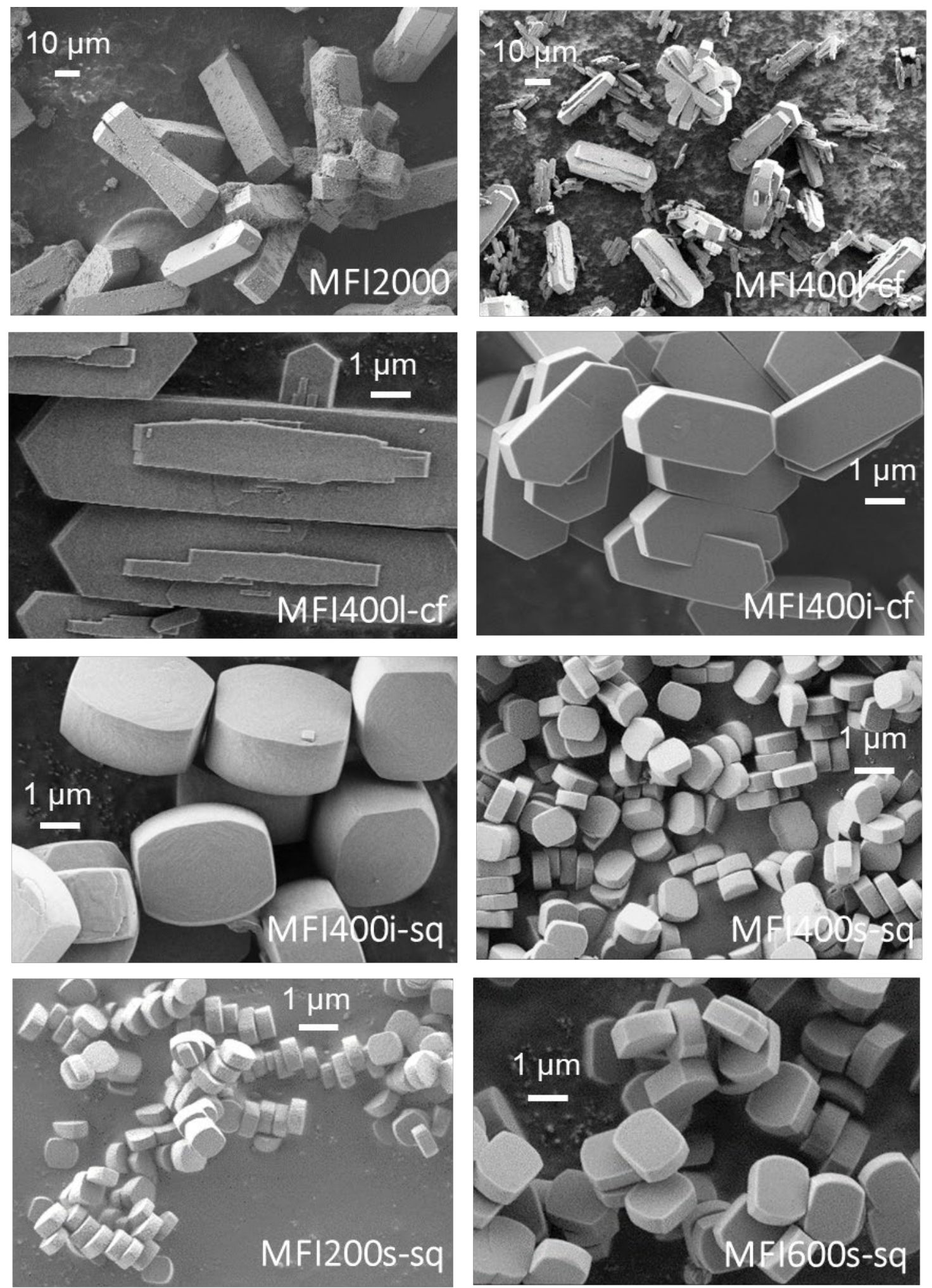

Figure 3. FESEM micrographs of the ZSM-5 zeolites. Note the different scale for the two top images (MFI2000 and MFI4001-cf). 


\subsection{Catalytic performance for the butenes cracking reaction}

The butenes cracking reaction over acid ZSM-5 catalysts is a complex process. It involves oligomerization-cracking reactions yielding propene and ethene accompanied by side reactions leading to undesirable products, such as aromatics and paraffins (Scheme 1). In a first step, 1-butene is protonated by reacting with the Brönsted acid site of ZSM-5 leading to the formation of a $\mathrm{C}_{4}{ }^{+}$carbenium, which readily isomerizes into the other butene isomers. The direct cracking of the $\mathrm{C}_{4}{ }^{+}$is energetically disfavoured, since it involves the formation of unstable primary carbeniums, so a preferred route follows a bimolecular dimerization with a second butene molecule to form different octyl carbocations, depending on the combination of the $\mathrm{C}_{4}{ }^{=}$isomers. The $\mathrm{C}_{8}{ }^{+}$intermediates can then crack via beta-scission into either two $\mathrm{C}_{4}$ molecules, $\mathrm{C}_{3}+\mathrm{C}_{5}$ or $\mathrm{C}_{2}+\mathrm{C}_{6}$. In this step, $C_{3}$ and $C_{2}$ tend to remain as alkenes, especially ethene, whereas $C_{5}$ and $C_{6}$ intermediates can desorb as the corresponding alkenes or further crack into lighter olefins, since they both hold a $\mathrm{C}-\mathrm{C}$ bond to be cleaved by beta-scission. Additionally, the $\mathrm{C}_{5}-\mathrm{C}_{6}$ carbeniums may oligomerize leading to $\mathrm{C}_{6+}$ olefins that can further crack on the Brönsted acid sites. The $\mathrm{C}_{6+}$ alkenes can also be transformed by hydrogen transfer into an olefin, also holding a carbocation, which will cycle into naphthenic compounds that will be involved in hydrogen transfer, dehydrogenation, alkylation/de-alkylation and condensation reactions leading to aromatics and ultimately to coke. Whereas $\mathrm{C}_{3+}$ alkanes are mainly formed by hydride transfer from the corresponding alkenes, methane and ethane are produced, preferentially, by protolytic cracking of iso-paraffins or of the sidechains of alkyl-aromatics ${ }^{30,63-65}$. 


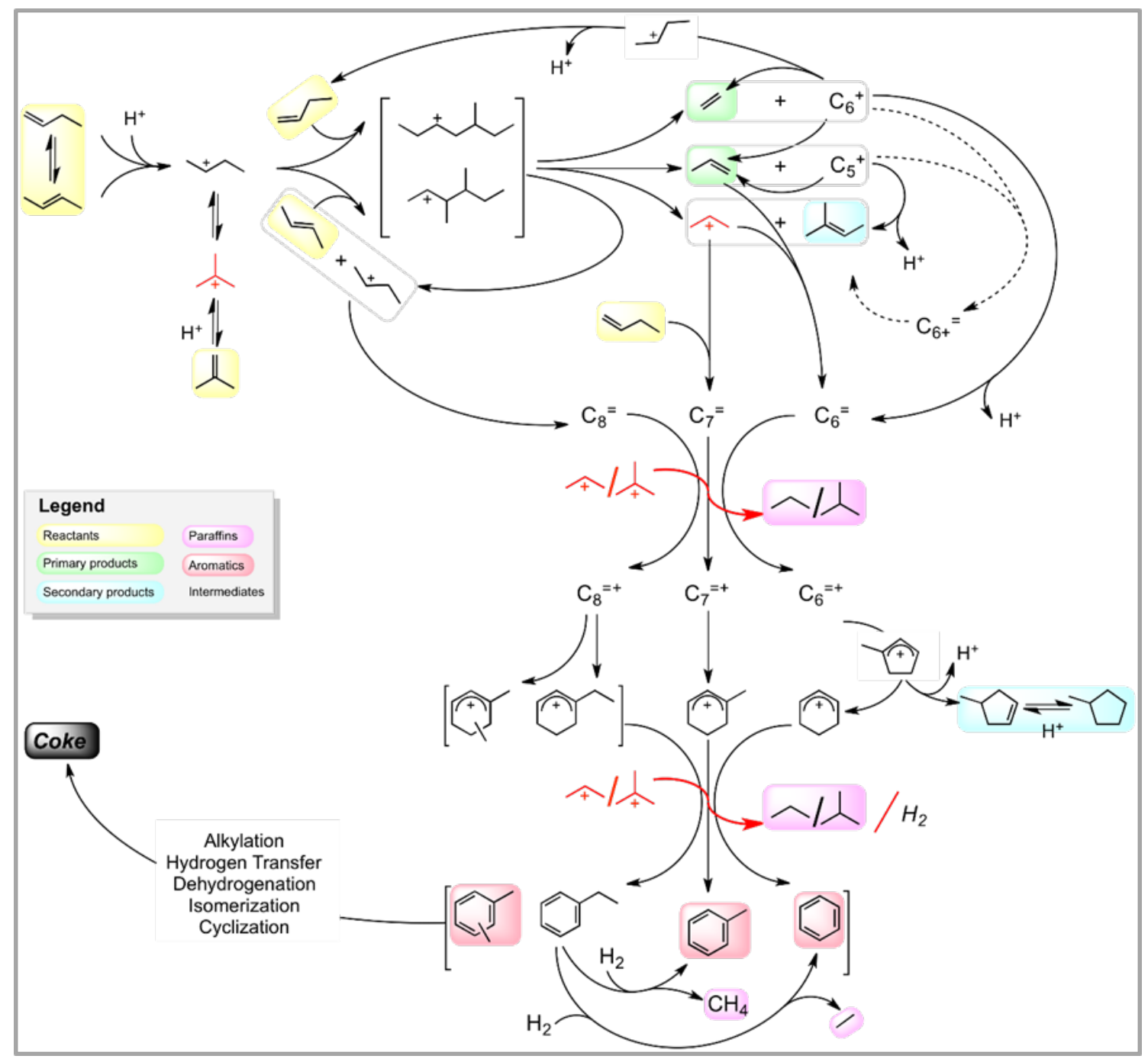

Scheme 1. Possible reaction routes for the butenes cracking over ZSM-5 catalysts on the basis of the most abundant products identified.

Taking into account the reaction mechanism described above, the optimal catalyst should be the one that, while being stable towards deactivation, will promote the propene selectivity by minimizing reactions leading to side-products, such as aromatics and alkanes. When cracking 1-butene, the thermodynamic equilibrium yield of propene and ethene increases with increasing reaction temperature and decreasing total pressure ${ }^{14,17,27,30,46,66}$. When catalysed by ZSM-5, optimum yields are obtained at reaction temperatures in the range of $500-580{ }^{\circ} \mathrm{C}$ and butenes partial pressure of $0.02-0.05 \mathrm{MPa}$, 
or at higher temperatures if partial pressure is increased. This is expected since increasing the reaction temperature favours the endothermic cracking steps over the exothermic hydrogen transfer reactions, while increasing pressure will favour kinetically the bimolecular reactions leading to hydrogen transfer. The 1-butene cracking tests described in the following sections were performed at $550^{\circ} \mathrm{C}$ and atmospheric pressure in a fixed bed reactor system.

\subsubsection{Influence of diffusional factors at comparable $\mathrm{Si} / \mathrm{Al}$ ratios}

Decreasing the crystal size of samples with comparable morphology and $a / b$ and $a / c$ "aspect ratios" will reduce the length of the sinusoidal and straight channels, facilitating diffusion and decreasing the extension of consecutive reactions, but will also increase the external surface exposed and the number of pore openings to the external surface, with possible consequences in product selectivity and coking ${ }^{42,67,68}$. The number of channel intersections will also be reduced, and this may affect the product distribution because in these crossing points the formation of aromatics will be favoured, as well as that of branched oligomers that will either crack to smaller products, or remain at the intersection leading to coke precursors ${ }^{69}$. Moreover, although according to DFT studies performed for Al-ZSM-5, Al has no thermodynamic preference for a specific framework position and Al siting will depend mainly on the synthesis procedure ${ }^{35}$, reducing the number of intersections will also reduce the amount of $\mathrm{Al}$ in these positions, reducing the extension of undesired bimolecular reactions. On the other hand, coffin- and square-shaped morphologies differ not only in their relative $a / b$ and $a / c$ dimensions but also in the continuity of the channels within the crystals. Coffin-type crystals have been described as being formed by different segments, including the tips at the extremes of the crystals along $c$ or the twinned sub-units growing on the (010) surfaces of the main crystals, that will hinder the diffusion of reactants and products ${ }^{41,58}$. These segments or components 
are separated by interfaces that may also act as diffusion barriers. Thus, the stronger diffusional limitations of coffin-type crystals are expected to result in faster deactivation as compared to the square-shaped morphology.

The intrinsic activity of the four ZSM-5 with $\mathrm{Si} / \mathrm{Al}=300$, both coffin- and square-shaped, is compared in Figure 4a with that of the large coffin-shaped ZMS-5 synthesized under fluoride media (MFI2000) with lower $\mathrm{Al}$ content $(\mathrm{Si} / \mathrm{Al}=786)$. Considering the three coffin-shaped zeolites, the initial butenes conversion increases when increasing crystal size, and the sample synthesized under $\mathrm{F}^{-}$media is by far the most active. This may be due to an enhancement of possible consecutive reactions involving the starting butenes and to higher diffusional restrictions within the larger crystal, increasing the residence time of the molecules within the micropores. However, when comparing the stability of these catalysts with time on stream (TOS) at the same contact time of $0.73 \mathrm{~h}$ (see Figure 4b), MFI2000 deactivates significantly faster, especially during the initial stages of the reaction. This can be a direct consequence of its larger crystals, which will promote the formation of coke precursors, especially at short TOS, when the activity of the catalyst is maximum. Moreover, taking into account that deactivation in micron-sized ZSM-5 has been related to external coke formation ${ }^{42}$, the small external surface and small number of pore openings will also contribute to its fast deactivation. 

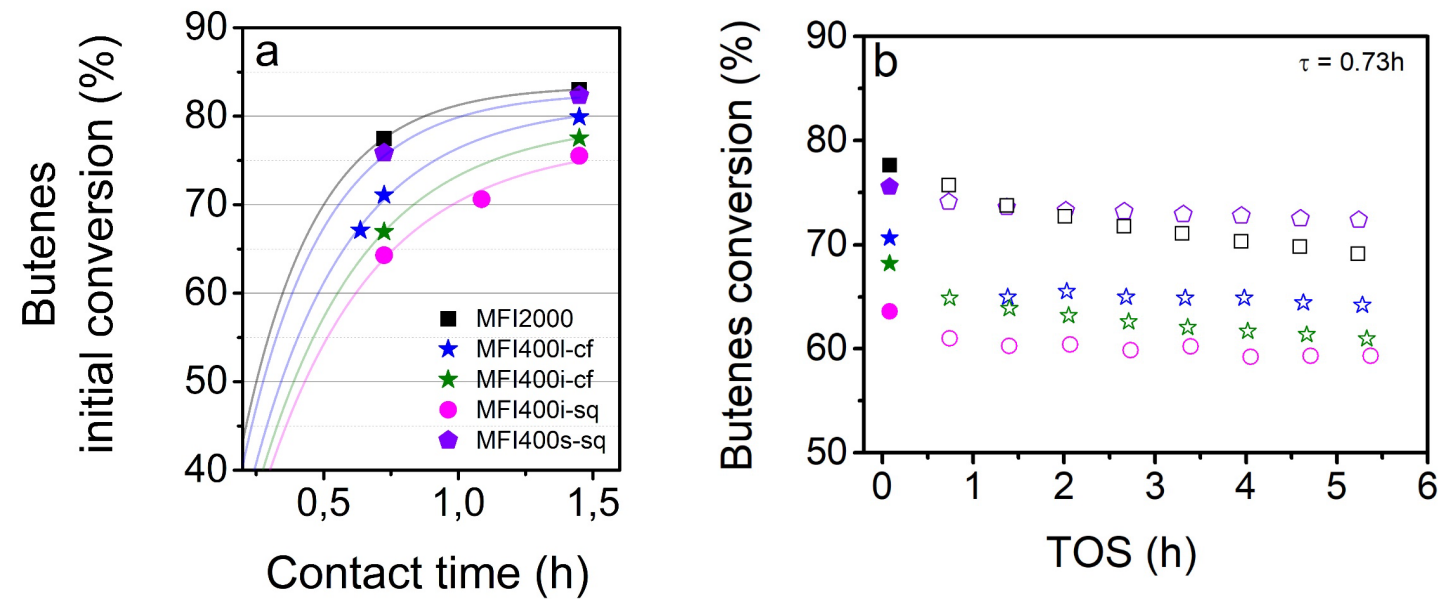

Figure 4. Initial butenes conversion at different contact times (a) and evolution of butenes conversion with TOS at contact time of $0.73 \mathrm{~h}$ (b) for MFI2000 and ZSM-5 catalysts with different size and morphology and Si/Al 300.

The sharp activity loss observed for MFI2000 at this contact time of $0.73 \mathrm{~h}$ is accompanied by a substantial drop of propene yield after 2-3 h TOS (see Figure 5a). Although the maximum propene yield obtained with MFI2000, $42.3 \mathrm{~mol} \%$ (39.8 wt \%) is, to the best of our knowledge, the highest propene yield reported over unmodified ZSM5 zeolite catalyst under similar reaction conditions ${ }^{14,19,23,32,33,39,70}$, it suffers a constant decrease after 2 hours on stream to values below $41.6 \mathrm{~mol} \%$. The decrease in propene yield is even more pronounced for catalyst MFI4001-cf, despite presenting comparable initial values, and for the third coffin-type ZSM-5, MFI400i-cf. 

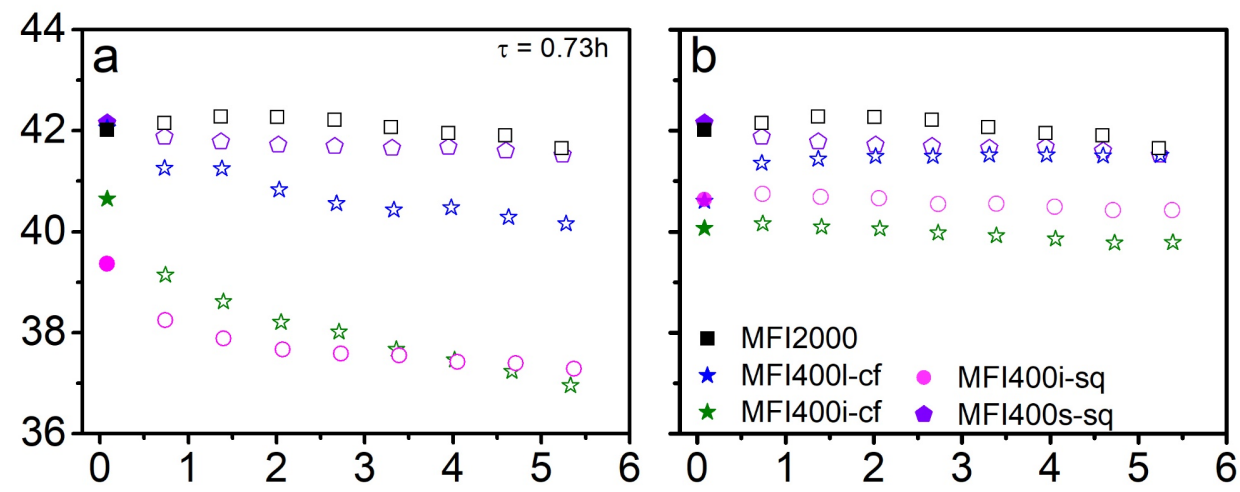

TOS (h)

Figure 5. Propene evolution with TOS for the MFI2000 and the ZSM-5 catalysts with different size and morphology and $\mathrm{Si} / \mathrm{Al} 300$ at a contact time of $0.73 \mathrm{~h}$ (a) and under conditions of maximum propene yield ( $\tau=0.73 \mathrm{~h}$ for MFI2000 and MFI400s-sq and $\tau=1.45 \mathrm{~h}$ for MFI4001cf, MFI400i-cf and MFI400i-sq) (b).

The two square-shaped ZSM-5, MFI400i-sq and MFI400s-sq, with intermediate and small crystal size, respectively, are also compared in Figures 4 and $\underline{5}$. The trend in terms of initial activity is the opposite as for the coffin-shaped catalysts, and reducing the crystal size from the micron- to the sub-micron size for the square morphology results in a huge increase of the initial butenes conversion. In fact, sample MFI400s-sq, with the smallest crystal size, is as active as the reference MFI2000 (see Figure 4a) but presents the additional advantage of being significantly more stable with TOS, despite its higher Al content (see Figure 4b), not only towards deactivation but also in terms of propene yield (maintaining ca. $41.6 \mathrm{~mol} \%$ after 2 hours on stream). Moreover, MFI400s-sq stands out for yielding the highest propene, not only when comparing with the rest of the catalysts at the same contact time (Figure 5a) but also under conditions of maximum propene production (Figure 5b). As will be discussed later in more detail, increased number of pore mouths and shorter diffusional paths for both straight and sinusoidal channels in this 
sample are the reason for this better performance. Regarding the influence of crystal morphology, coffin-shaped ZSM-5 present higher deactivation rates than square-shaped samples, independently of the crystal size, as could be expected from their larger diffusional limitations. Moreover, among the zeolites with coffin-type morphology, the one with intergrowths, MFI4001-cf, presents a lower deactivation rate than the other two zeolites with clean (010) surfaces and accessible straight channels.

The molar yield of the primary reaction products is plotted versus butenes conversion in Figure 6 for the MFI2000 and the four catalysts with Si/Al 300, tested at different contact times. At similar conversion ranges, these plots allow comparing the catalysts in terms of molar selectivity. Please note that in these graphs, the yield at the highest conversion data, obtained at a given contact time, corresponds to the yield observed at initial TOS (closed symbols). In this way, and taking propene as example (Figure 6a), the rest of the points (open symbols) correspond to the propene yields at increasing TOS in Figure 5 and, therefore, affected by the deactivation of the catalyst. For all the catalysts, propene is the dominant reaction product, followed by ethene, $\mathrm{C}_{5+}$ aliphatics and aromatics. Figure $6 \mathrm{a}$ shows a maximum in propene selectivity for a conversion range of $70-77 \%$ for all catalysts except MFI400s-sq, where the maximum is expected to be shifted towards conversions above $75 \%$. The propene selectivity starts to decrease at higher conversion values, and confirms its primary unstable nature. Propene yield declines in favour of an increase in aromatics, which appear as secondary stable products and will, eventually, drive into catalyst decay. Regarding ethene and $\mathrm{C}_{5+}$ aliphatics, according to the selectivity curves, the former presents a primary plus secondary stable character, whereas the aliphatic hydrocarbons are unstable for the conversion range considered.

Among the coffin-shaped catalysts, MFI2000 is the most selective to propene and ethene, but also highly selective to aromatics, and presents the lowest selectivity to $\mathrm{C}_{5+}$ aliphatics. 
Thus, the $\mathrm{C}_{5+}$ fraction, mainly alkenes, is converted to a larger extend in this large crystal ZSM-5 with a higher proportion of channels intersections, either by cracking into the desired light olefins, or by cyclisation and further conversion into aromatics. The rapid activity loss of MFI2000 suggests that, although part of the aromatics are able to egress the crystals, another fraction remains within the zeolite structure, participating in coking reactions leading to deactivation.

As the crystal size of coffin-like crystals is decreased, propene selectivity decreases also, especially for the sample with intermediate crystal size, MFI400i-cf, which, on the other hand, maintains a high selectivity to aromatics, but also to $\mathrm{C}_{5+}$ aliphatics. Taking into account the crystal dimensions for these three samples it can be seen that, besides the overall crystal size reduction, the relative length of the crystals along the $a$ and $b$ axis, parallel to the sinusoidal and straight channels, respectively, and given by the $a / b$ ratio (see Table 1), also varies. In the three cases, the crystals are longer in the $a$ direction than in the $b$ direction $(a / b>1)$ but MFI400i-cf has a significantly higher $a / b$ ratio, and therefore proportionally longer sinusoidal channels than the other two zeolites. Aromatics will diffuse preferentially through the straight channels running along the $b$-axis, whereas smaller hydrocarbons such as propene will egress the crystals through the sinusoidal channels along $a^{42,67,68}$. However, sinusoidal channels tend to deactivate faster due to the formation of external surface coke species ${ }^{42}$, decreasing the contribution of these channels and, therefore, increasing the selectivity to aromatics when comparing MFI400i-cf with MFI2000. The propene selectivity obtained with MFI4001-cf, although lower than that corresponding to MFI2000 in the high conversion range $(>75 \%)$, is similar to the latter when comparing at lower conversions. Moreover, it shows lower aromatic selectivity as compared to the other two coffin-shaped ZSM-5, and higher aliphatic $\mathrm{C}_{5+}$ oligomers than MFI2000 (with lower Si/Al). The main difference of MFI4001-cf as compared to the other 
two catalysts with this coffin-type morphology is that it presents intergrowths that will reduce the number of pore mouths corresponding to the straight channels, while increasing the proportion of openings giving access to the sinusoidal pores. Thus, the contribution of the sinusoidal channels in this catalyst will be significantly higher. According to a recent study, the formation of aromatics ${ }^{42}$ and their diffusion ${ }^{41}$ within the zig-zag channels is less favoured than within the straight pores, and this could explain the differences in selectivity observed for the twinned MFI4001-cf catalyst. On the other hand, the other two coffin-shaped ZSM-5, without intergrowths, will have clean (010) surfaces and open straight channels along $b$ that will favour the diffusion of the aromatics formed in the channel intersections, increasing the aromatic selectivity. Thus, in the case of ZSM-5 catalysts with coffin-shaped crystals the highest propene and lowest aromatic selectivity is obtained for sample MFI4001-cf, which is not the one with the smallest crystals but the only coffin-type ZSM-5 with intergrown twinned crystals. For the nonintergrown coffin-shaped zeolites, the higher the relative length of the crystal along $a$ (parallel to the sinusoidal channels) vs the crystal dimension along $b$ (parallel to the straight pores), the lower the propene.

Regarding the square-shaped ZSM-5, decreasing crystal size results in a higher propene selectivity. As pointed out above, for the small crystal sized zeolite, MFI400s-sq, propene selectivity follows an increasing trend with conversion, even for values over $75 \%$. This clearly differs from the rest of the zeolites compared, and could be related to the shorter diffusional paths along both, the sinusoidal and the straight pores, which will enable primary cracking products, such as propene, to egress the crystal before getting involved in undesired consecutive oligomerization or oligomerization + cyclisation reactions that will preferentially take place in the channel intersections ${ }^{35}$, present in a lower amount in 
the small MFI400s-sq crystals. This is in good agreement with the low selectivity of this small-crystal ZSM-5, not only to aromatics, but also to aliphatic $\mathrm{C}_{5+}$ products.

The crystal size and morphology study shows that it is possible to improve the catalytic behaviour of the conventional large coffin-shaped high silica ZSM-5 crystals for the production of propene through butene cracking by preparing samples with sub-micron sized crystals, square morphology and $\mathrm{Si} / \mathrm{Al} \sim 300$. These catalysts have shorter diffusional paths and more pore openings, which favour the diffusion of propene out of the crystals and reduce the extent of undesired consecutive reactions leading to aromatics or to an accumulation of coke precursors in the micropore channels.
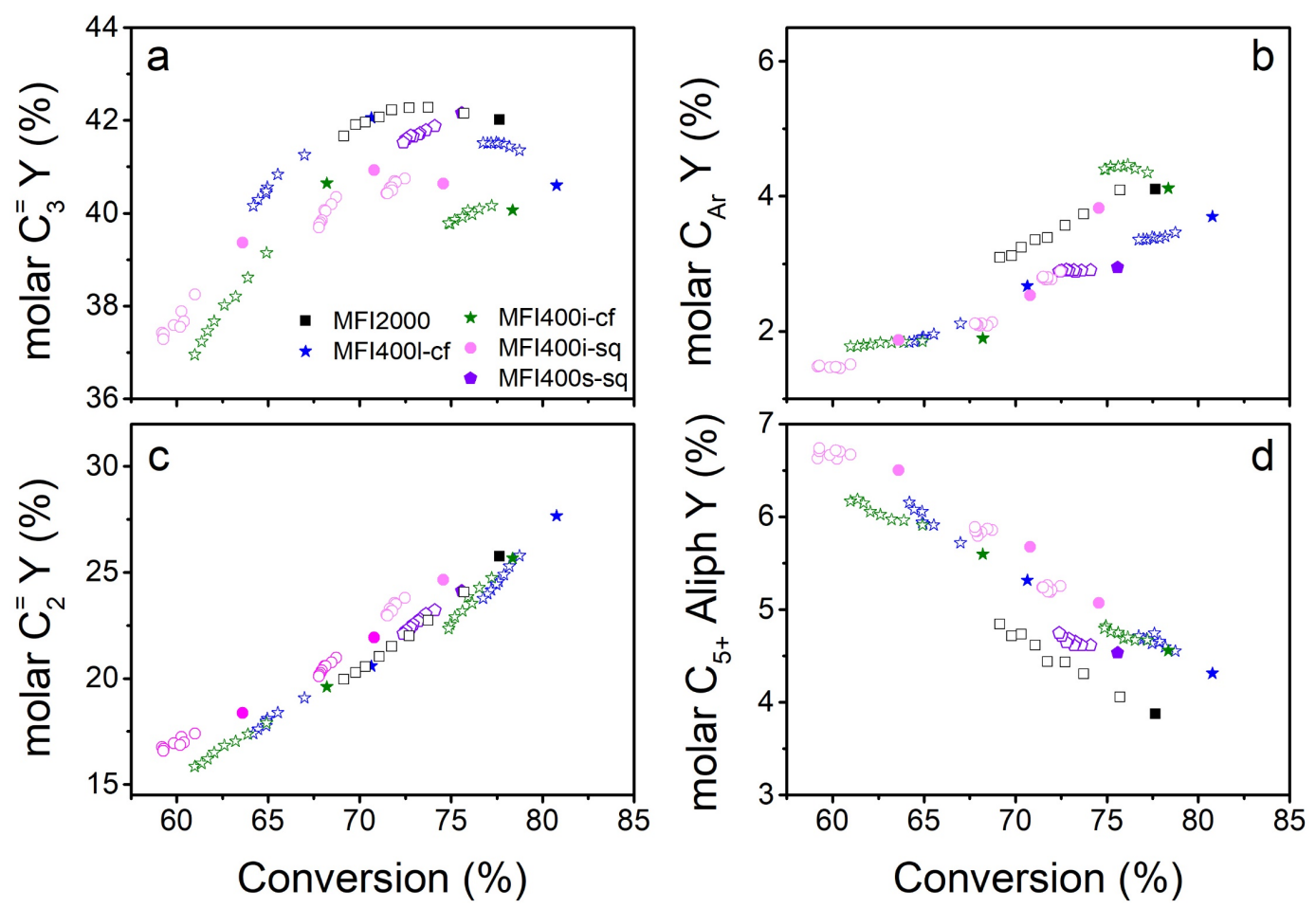

Figure 6. Propene (a), aromatics (b), ethene (c) and $\mathrm{C}_{5+}$ aliphatic (d) molar yield as a function of butenes conversion for MFI2000 and the ZSM-5 catalysts with different size and morphology and $\mathrm{Si} / \mathrm{Al} 300$.

\subsubsection{Influence of compositional factors for the small-crystal ZSM-5 catalysts.}


In a second approach, the effect of modifying the $\mathrm{Si} / \mathrm{Al}$ ratio will be studied for the ZSM5 zeolite with small size square-shaped crystals, which is the best performing in terms of activity, catalyst life and propene selectivity. Thus, two new samples, with $\mathrm{Si} / \mathrm{Al}$ in the final solid of ca. 500 and 150 (MFI600s-sq and MFI200s-sq, respectively) have been compared with the best performing catalyst, MFI400s-sq, with Si/Al 300. According to theoretical studies, Al has no thermodynamically preferred positions within the MFI structure, and the higher the $\mathrm{Si} / \mathrm{Al}$ ratio, the lower the differences among the energy values obtained for the different possible locations ${ }^{35}$. Thus, Al siting will be mainly determined by the synthesis procedure, such as the presence of $\mathrm{Na}$ or specific organic structure directing agents (OSDA) ${ }^{71}$, or competitive incorporation of other trivalent elements ${ }^{35}$. Taking into account the low Al contents of the three ZSM-5 samples compared in this section, and that have been synthesized following the same procedure, except for the amount of Al precursor added to the synthesis gel, no significant differences are expected regarding their $\mathrm{Al}$ distribution.

Despite the high $\mathrm{Si} / \mathrm{Al}$ ratios (above 150), the intrinsic activity of the ZSM-5 catalysts is significantly influenced by the aluminium content, and higher amount of $\mathrm{Al}$ results in higher initial butenes conversion (Figure 7a). Moreover, an additional experiment carried out with a silicalite analogue $(\mathrm{Si} / \mathrm{Al}>3000)$ under the same reaction conditions, confirmed a virtually null 1-butene conversion into products different from butene isomers (Table S1). Although previous studies ${ }^{14,70}$ suggested that weak acidic silanol groups are the catalytically active sites for the butenes cracking to propene and the more acidic bridged $\mathrm{OH}$ groups promote secondary reactions towards alkane and aromatics, we see that, under our reaction conditions, the presence of bridged hydroxyl groups are needed to catalyse the butenes cracking reaction towards an appreciable propene production. 
When the catalysts are tested at the same contact time (Figure 7b), although differences are not large, the deactivation rate is lower for the catalyst with more $\mathrm{Al}$ (which is also the most active). Although an increase in stability when increasing Si/Al ratio of ZSM-5 zeolites has been reported for zeolites with $\mathrm{Si} / \mathrm{Al} \leq 200$, because zeolites with low density of acid sites show lower coking formation tendency $y^{20,25}$, we observe the opposite trend for our small-crystal square-shaped ZSM-5 zeolites with $\mathrm{Si} / \mathrm{Al} \geq 200$. This can be explained on the bases that a catalyst with very low amount of active sites (very high $\mathrm{Si} / \mathrm{Al}$ ratio) will reduce drastically its initial activity when a number of acid sites are deactivated with time on stream, as compared with a catalyst with more acid sites (lower $\mathrm{Si} / \mathrm{Al}$ ratio), which will retain longer its activity when losing the same number of acid sites. Taking into account that for these zeolites the right crystal size and morphology minimize the formation of coke precursors, the effect of reducing the Al content and, therefore, the amount of active sites, will only have a negative influence on initial activity and catalyst life under our conditions, and the larger amount of active sites in the sample with higher Al content will result in a higher stability of this catalyst with TOS. In fact, when compared at different contact times but comparable initial butenes conversion, deactivation rates are rather similar for the three catalysts (Figure S1b). Thus, when comparing catalysts with similar -and relatively small- crystal size, the Al content has a significant influence on the activity for butene conversion, but the effect regarding catalyst deactivation is minor for the TOS range considered. 

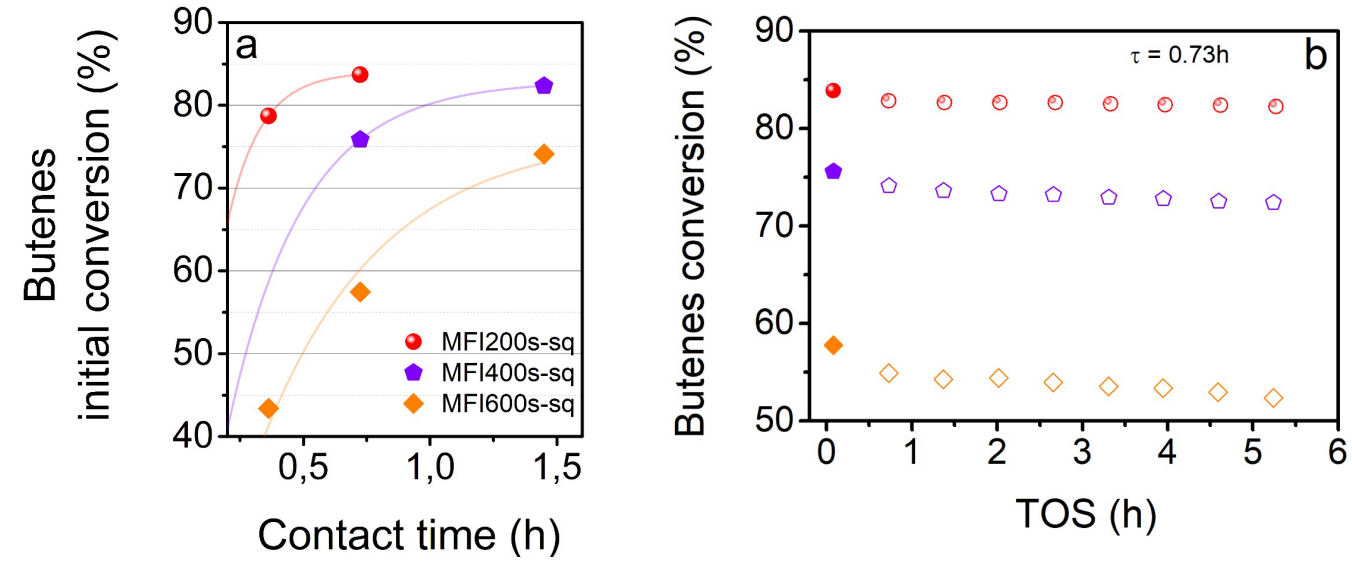

Figure 7. Initial butenes conversion at different contact times (a) and evolution of butenes conversion with TOS at contact time of $0.73 \mathrm{~h}$ (b) for the small-sized crystals at different $\mathrm{Si} / \mathrm{Al}$ ratios.

However, the $\mathrm{Si} / \mathrm{Al}$ ratio has an important effect on the product distribution at the reactor outlet. Although the propene yield of the less active MFI600s-sq is the lowest, the most active catalyst, MFI200s-sq, also produces less propene than the catalyst with intermediate $\mathrm{Al}$ content, MFI400s-sq (Figure 8a). MFI400s-sq yields more propene than the other two zeolites, not only at the same contact time of $0.73 \mathrm{~h}$, but also under conditions of maximum propene production (igure 8b). Moreover, the stability of propene yield with TOS is also the highest for this catalyst.
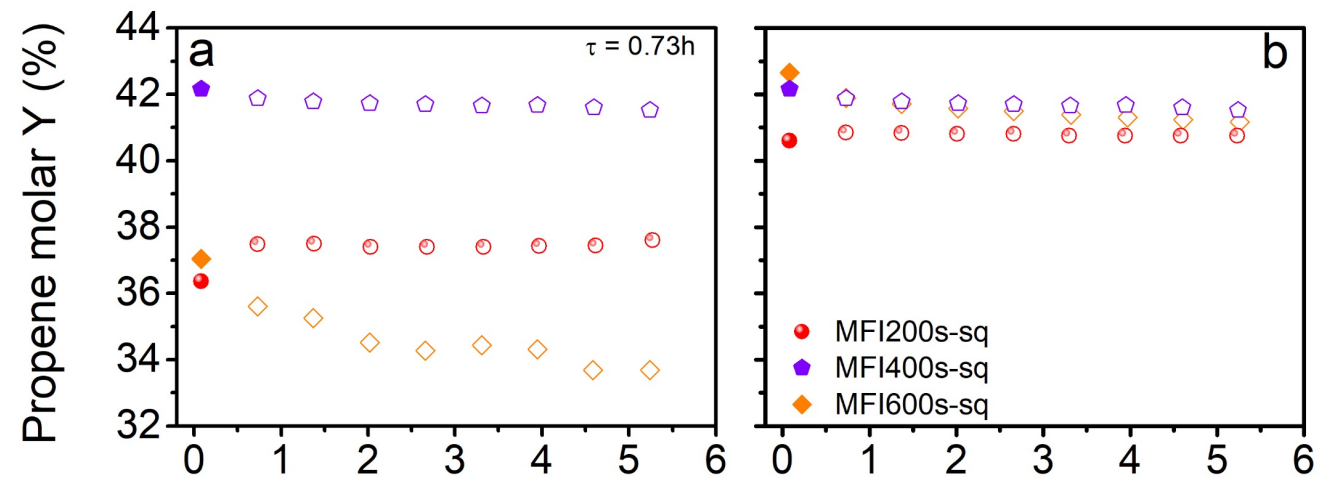

TOS (h) 
Figure 8. Propene evolution with TOS for the small-sized crystals at different $\mathrm{Si} / \mathrm{Al}$ ratios at a contact time of $0.73 \mathrm{~h}$ (a) and under conditions of maximum propene yield ( $\tau=0.73 \mathrm{~h}$ for MFI400s-sq, $\tau=1.45 \mathrm{~h}$ and $0.36 \mathrm{~h}$ for MFI600s-sq and MFI200s-sq, respectively) (b).

According to the molar selectivity plots ( $\underline{\text { Figure 9) }}$, MFI600s-sq catalyst is less selective to aromatics (as expected for the lower $\mathrm{Al}$ content) and to ethene, whereas the $\mathrm{C}_{5+}$ aliphatic yield is increased with respect to MFI400s-sq sample. The lower activity of this small crystal catalyst with highest $\mathrm{Si} / \mathrm{Al}$ ratio limits secondary reactions and thus the transformation of the higher aliphatic oligomers into aromatics. Increasing the Al content to the levels of MFI200s-sq enhances the cracking activity, but also promotes side reactions causing a lower selectivity to propene, which is accompanied by an increase in aromatics. Ethene and $\mathrm{C}_{5+}$ aliphatics selectivity are rather similar than those of MFI400ssq catalyst. Thus, the formation of aromatics is promoted at the expense of propene for the catalyst with the highest $\mathrm{Al}$ content as compared with the other two catalysts of this series. Although part of the aromatic molecules may form poly-alkylated species, which will be retained in the pores of the crystals leading to catalyst decay, especially at short TOS, the deactivation rate for the three catalysts of this series is lower as compared with the ZSM-5 catalysts with crystals larger than $1 \mu \mathrm{m}$. This underlines the beneficial effect of reducing the crystal dimensions for the ZSM-5 catalyst in terms of catalyst stability, regardless of the $\mathrm{Al}$ content. 

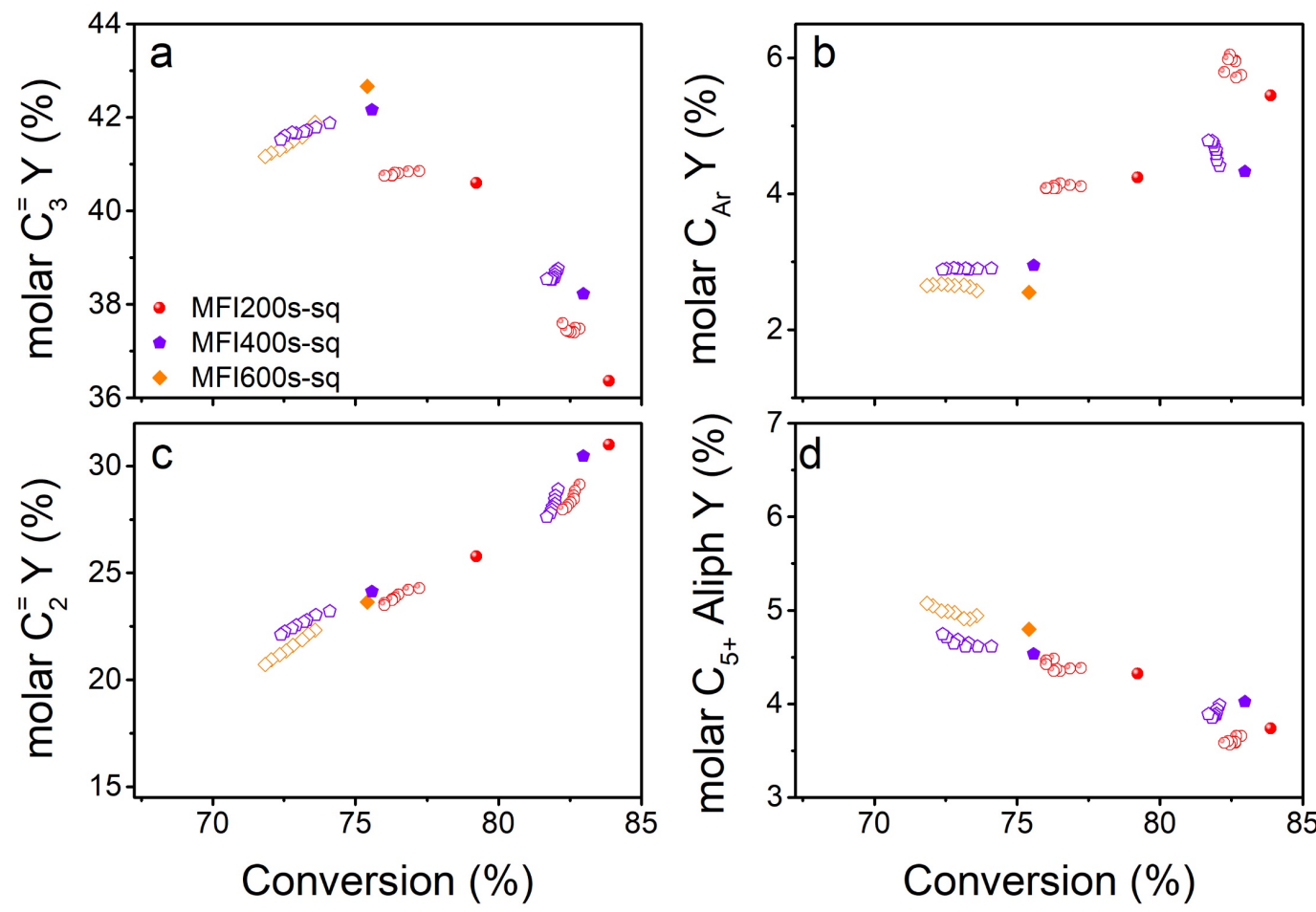

Figure 9. Propene (a), aromatics (b), ethene (c) and $\mathrm{C}_{5+}$ aliphatic (d) molar yield as a function of butenes conversion for the small-sized crystals at different $\mathrm{Si} / \mathrm{Al}$ ratios.

Summarizing, when modifying the Al content in small sized ZSM-5 catalyst with square morphology, the catalyst stability is maintained, and the main influence of the $\mathrm{Si} / \mathrm{Al}$ ratio is on the catalytic activity, with higher butene conversions for higher $\mathrm{Al}$ contents, and on propene selectivity, which is significantly penalized for the sample with the lowest $\mathrm{Si} / \mathrm{Al}$ ratio, MFI200s-sq. Thus, intermediate $\mathrm{Al}$ content ( $\mathrm{Si} / \mathrm{Al}$ ca. 300) leads to optimum performance.

\subsubsection{Influence of diffusional and compositional factors on potential butenes to} propene production routes. 
In the previous sections, the catalytic results have been tentatively interpreted based on general reaction routes involving the four main components, propene, ethene, aromatics and $\mathrm{C}_{5+}$ aliphatics. According to this general mechanism, propene is obtained by dimerization and selective cracking of octyl carbenium intermediates to propene and pentenes and/or to ethene and hexenes, less favourable ${ }^{15}$. Cracking of pentenes and hexenes can yield additional propene, and other reactions such as hydride transfer, cyclisation and aromatization, will lead to the formation of undesired aromatics and coke precursors $^{14,15}$. When we compared the selectivity of the MFI catalysts with similar Si/Al ratio, we observed a high selectivity to propene for the catalysts with large coffin-shaped crystals, especially for MFI4001-cf. This catalyst, with higher proportion of sinusoidal channels due to the intergrowth of twinning crystals, will present larger steric hindrance disfavouring the formation and/or diffusion of aromatics, as compared to the other coffinshaped zeolites with clean [010] surfaces and open straight 10-ring channels. MFI4001-cf is also the most stable towards deactivation among the coffin-shaped ZSM-5, in good agreement with its lower aromatization selectivity. Larger crystals also imply higher proportion of channel intersections (crossing between sinusoidal $/ a$-oriented and straight/ $b$-oriented MFI channels) where the formation of branched oligomers, easier to crack may be enhanced. The formation of the aromatics will also be favoured when increasing the number of channel intersections, but their diffusion along the sinusoidal channels will be severely hindered. In the case of crystals presenting open straight channels (coffin-shaped without intergrowth) the aromatics formed may diffuse out of the crystals, but may also be further converted into coke precursors, leading to faster catalyst deactivation as compared to the ZSM-5 with square-type morphology, because of the stronger diffusional limitations imposed by the interfaces within the coffin-shaped crystals. Among the square-shaped zeolites, the catalyst with $\leq 1 \mu \mathrm{m}$ crystals (MFI400s- 
sq) is highly selective to propene due to the fast diffusion of this product out of the small sized zeolite crystals.

Except for small -sub-micron- crystals, intracrystalline diffusion will dominate the transport of products in ZSM-5 zeolites, including that of the non-desired aromatics ${ }^{72,73}$. Longer diffusional paths and, therefore, more channel intersections, may enhance cyclization vs cracking, increasing the formation of aromatics. On the other hand, the sinusoidal channels present stronger steric and diffusional limitations as compared to the straight pores. Thus, a higher proportion of sinusoidal vs. straight pores may allow more re-cracking events but will also prevent the formation and/or diffusion of large (poly)alkylated aromatic molecules. Finally, due to the molecular traffic control effect ${ }^{74}$ light hydrocarbons such as ethene and propene will preferentially diffuse through the sinusoidal channels without being further converted into bulkier products, while being consumed in consecutive reactions along the straight channels ${ }^{67,68}$. Regarding the influence of $\mathrm{Si} / \mathrm{Al}$ ratio in small square-shaped ZSM-5 catalysts, intermediate aluminium contents $(\mathrm{Si} / \mathrm{Al} \sim 300)$ were seen to maximize propene selectivity. Higher $\mathrm{Si} / \mathrm{Al}$ ratios penalize catalyst activity whereas lower $\mathrm{Si} / \mathrm{Al}$ ratios will increase selectivity to aromatics.

In order to fully understand the role of the three catalyst descriptors (crystal size, crystal morphology and $\mathrm{Si} / \mathrm{Al}$ ratio) on the ability of ZSM-5 based catalyst for the selective production of propene by butenes cracking, a more detailed analysis of the product distribution has been performed (see Figures S2-S4).

The four main products described so far have been propene, ethene, aromatics, and the $\mathrm{C}_{5+}$ aliphatic fraction, which is composed mainly by $\mathrm{C}_{5}$ olefins for all catalysts (see Figure S2). The most abundant among the different pentene isomers is 2-methyl-2-butene (2M2B), produced by beta-scission of octyl carbenium ions following the most favoured cracking reaction paths involving secondary-tertiary and secondary-secondary type of 
carbenium ions $^{15,75}$ (see Scheme 1). The three catalysts that were more selective to propene, MFI2000, MFI4001-cf and MFI400s-sq, show the lowest selectivity to 2M2B (Figure S2c). Under our experimental conditions and in the presence of ZSM-5 catalysts, bimolecular oligomerization of 2M2B with other olefins and further cracking of these heavier oligomers to light olefins will prevail over its direct cracking by beta-scission ${ }^{71}$, and this agrees with low selectivity to ethene obtained with these three samples (see Figure $6 \mathrm{c}$ ). The lower production of $\mathrm{C}_{6+}$ aliphatic hydrocarbons observed in all cases suggests that they are more easily converted through secondary reactions before escaping the zeolite pores, such as cracking and/or aromatization via $\mathrm{C}_{6}{ }^{+}$olefin hydride elimination and cyclisation, whereas pentenes, less reactive, escape the pores mainly as amylenes.

A thorough product distribution within the paraffinic fraction is given in Figure S3. The first thing to remark is that catalyst MFI2000, which was highly selective to aromatic hydrocarbons (see Figures 6 and S4a-d) is significantly less selective to paraffins (see Figure S3a) than the other two coffin shaped ZSM-5. However, this is mainly due to lower methane and ethane yields (see Figure S3b), which may be formed by protolytic cracking of branched alkanes, but also by protolytic side-chain cracking of long-chain alkylaromatics $^{63-65}$. This suggests that these alkylaromatics, when formed in MFI2000, are more likely to suffer condensation/cyclisation reactions than cracking when diffusing through the long straight channels along $b$. When comparing the catalysts synthesized with $\mathrm{Si} / \mathrm{Al}=400$, the small-square-shaped crystal MFI400s-sq presents higher selectivity to paraffins than the coffin-shaped ZSM-5, despite its lower production of aromatics (see Figures 6 and $\mathrm{S} 4 \mathrm{a}-\mathrm{d})$. It is, however, the less selective to $\mathrm{C}_{1}$ and $\mathrm{C}_{2}$, and this can be explained by the easier diffusion of the alkylaromatics out of the short straight channels in MFI400s-sq, that will reduce the probability of side-chain cracking, even for small crystal ZSM-5 with higher aluminum content, such as MFI200s-sq. However, MFI400s- 
sq yields the highest amount of $\mathrm{C}_{3}+\mathrm{C}_{4}$ paraffins, including $\mathrm{i}-\mathrm{C}_{4}$, not only when compared to the square-shaped zeolite with intermediate crystal size, MFI400i-sq, but also when compared to the coffin-shaped catalysts, and this fraction does increase with increasing Al contents. The $\mathrm{C}_{3+}$ paraffins will be formed, preferentially, by hydrogen transfer of naphthenes to the corresponding olefins, leading in this way to the formation of aromatics. Following this mechanism, the formation of one aromatic molecule from a $\mathrm{C}_{3}-\mathrm{C}_{6}$ alkene by successive HT and cyclisation should be accompanied, theoretically, by the formation of three paraffin molecules ${ }^{76,77}$. However, aromatics may also be formed by a direct dehydrogenation-aromatization mechanism producing $\mathrm{H}_{2}{ }^{15}$, leading to lower paraffins to aromatic ratios. Taking into account both routes leading to aromatics, the sum of paraffins and $\mathrm{H}_{2}$ should be three times the total moles of aromatics. This is, in fact, observed by Lin et $\mathrm{al}^{15}$, and when $\mathrm{H}_{2}$ is not considered, the paraffin-to-aromatic molar ratios are below 2, in good agreement with those obtained under our conditions. Figure 10 shows that, although the $\mathrm{C}_{3}-\mathrm{C}_{6}$ paraffins-to-BTX ratio is below 3 in all cases, the highest values in the $70-80 \%$ conversion range are obtained for catalyst MFI400s-sq, indicating that for this catalyst the hydrogen transfer mechanism is preferred over the formation of aromatics. On the other hand, this ratio is particularly low for MFI2000 and MFI400i-cf. This suggests that for these two coffin-shaped catalysts, the formation of aromatics does not proceed only by hydrogen transfer, but their formation following a direct dehydrogenation-aromatization route is enhanced as compared to the rest of the catalysts. 


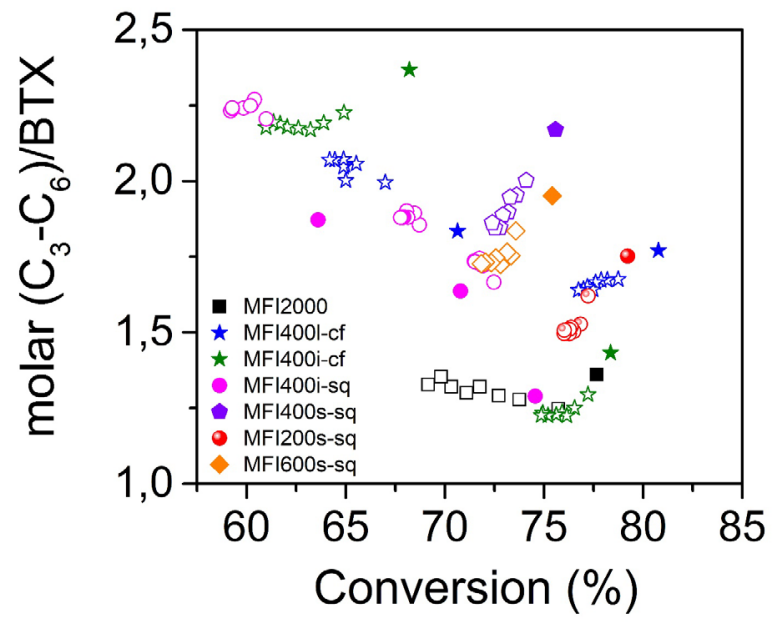

Figure 10. Paraffins-to-Aromatics molar ratio as a function of butenes conversion for the different ZSM-5 catalysts.

Regarding the selectivity to BTX aromatics (see Figure S4), it is maximized for the smallcrystal MFI200s-sq with the highest $\mathrm{Al}$ content, which presented high selectivity to $\mathrm{C}_{3+}$ paraffins, but also for the large crystal MFI2000 and for MFI400i-cf in the high conversion range $(>75 \%)$. Zeolite MFI4001-cf, presenting intergrown crystals, is less selective to aromatics than the other two coffin-shaped zeolites, due to the higher proportion of sinusoidal channels in the former, which will limit the formation and/or diffusion of aromatics, as discussed above. Aromatics distribution within the BTX fraction also varies when comparing the different catalysts. Toluene, which can be formed from $\mathrm{C}_{7}$ intermediates via dimerization of propene and butene followed by hydrogen transfer steps to the cycloalkane intermediate and further aromatization, is the main aromatic compound in all cases (Figure $\mathrm{S} 4 \mathrm{c}$ ). As compared to the $\mathrm{C}_{7}$ cyclisation to toluene, $\mathrm{C}_{6}$ and $\mathrm{C}_{8}$ intermediates show lower tendency to form benzene and xylenes, respectively. In fact, higher activation energies were reported for the closure of the $\mathrm{C}_{6}$ 
ring to benzene as compared to that to toluene for propane aromatization reactions over modified ZSM-5 based catalyst ${ }^{78}$. The two samples with a higher aromatization selectivity, MFI2000 and MFI200s-sq, present higher selectivity to benzene than the rest of the catalysts (see Figure S4b), and this agrees with their lower molar yield to methylciclopentenes (see Figure S4e), which will be converted into benzene via ring expansion to cyclohexenes followed by aromatization ${ }^{76}$. In the case of MFI2000, the large crystals (high number of channel intersections) and the long open straight pores will favour aromatization even for very low $\mathrm{Al}$ contents $(\mathrm{Si} / \mathrm{Al}=786$ in the final zeolite), leading to fast deactivation of the catalyst, and direct dehydrogenation will have an important contribution to the formation of these undesired by-products. Moreover, the large crystals will also impose more severe diffusion restrictions and the less hindered aromatic compounds, such as benzene or toluene, will preferentially egress the microporous structure, while bulkier aromatics will either dealkylate or further react leading to coke prcursors ${ }^{15}$. In the case of the small square-shaped ZSM-5, MFI200s-sq, with lower diffusional restrictions, the higher $\mathrm{Al}$ content does not penalize catalyst life under our experimental conditions, but results in high selectivity to aromatics and $\mathrm{C}_{3}-\mathrm{C}_{4}$ paraffins formed by hydrogen transfer reactions. Zeolite MFI400i-cf, with intermediate coffin-shaped crystals but with sub-micron dimension along the $b$-axis, parallel to the straight channels, of $0.5 \mu \mathrm{m}$, is highly selective to aromatics at high conversion levels where the formation of these aromatics is favoured, and presents the highest selectivity to xylenes, which will easily egress the zeolite crystals through the short straight channels.

The reason for the differences in aromatics selectivity when comparing MFI2000 with the rest of the catalysts can be deduced from the correlations enclosed in Figure 11, where the accumulated yields to benzene, $\mathrm{m}+\mathrm{p}$-xylenes, o-xylene and trimethylbenzene (TMB) are plotted vs the accumulated yield to toluene, the most abundant aromatic compound in 
all cases. These accumulated or integrated yields correspond to the amount of the aromatic hydrocarbon produced during a certain time on stream and detected at the reactor outlet, so the products trapped within the crystal micropores will not contribute. Since the catalysts show a higher deactivation rate for the first 2 hours on stream, we compare the diffusion of the less hindered molecules (benzene and toluene) with those that may be more diffusion impeded (xylenes and TMB $)^{41,52}$ during this period. The integrated yields to toluene and benzene (Figure $11 \mathrm{a})$ are very well correlated $\left(\mathrm{R}^{2}=0.99\right)$, indicating that they diffuse similarly through the channels of all the catalysts, including the large crystal zeolites MFI2000 and MFI4001-cf. The same applies to the toluene versus $m+p$-xylene correlation (Figure 11b) when excluding the large crystal MFI2000, which deviates from the line, suggesting that $m+p$-xylene, especially $m$-xylene, suffer stronger diffusion limitations in this catalyst. The longer intra-crystalline residence time in the very long straight channels will enhance the participation of $\mathrm{m}+\mathrm{p}$-xylene in consecutive reactions leading to coke precursors before desorbing from the crystal. It should be noted that the benzene/toluene linear correlation gives a negative intercept, indicating, as pointed above, that the formation and diffusion of toluene is faster than that of benzene. On the other hand, the $\mathrm{m}+\mathrm{p}$-xylene/toluene line gives a positive intercept, that may be ascribed to the faster diffusion of $\mathrm{p}$-xylene with respect to toluene ${ }^{79}$. As the aromatic compounds get bulkier (Figures 11c and d), not only catalyst MFI2000 but also the large crystal coffinshaped MFI4001-cf deviate from the general trend, evidencing increased transport restrictions within the micropore system of this catalyst, with a higher proportion of sinusoidal pores ${ }^{41}$. In the case of catalyst MFI400i-sq, with long straight channels along $b$ but square-shaped crystals, the deviation is observed only for the correlation corresponding to the bulkiest product analyzed, TMB. On the other hand, catalyst MFI600s-sq, with small square-shaped crystals and lower Al content, presents higher o- 
xylene/toluene and $\mathrm{TMB} /$ toluene molar ratios than the rest of the catalysts. This can be explained by the lower probability of primary aromatic products to be involved in consecutive reactions, such as alkylation but also dealkylation reactions.
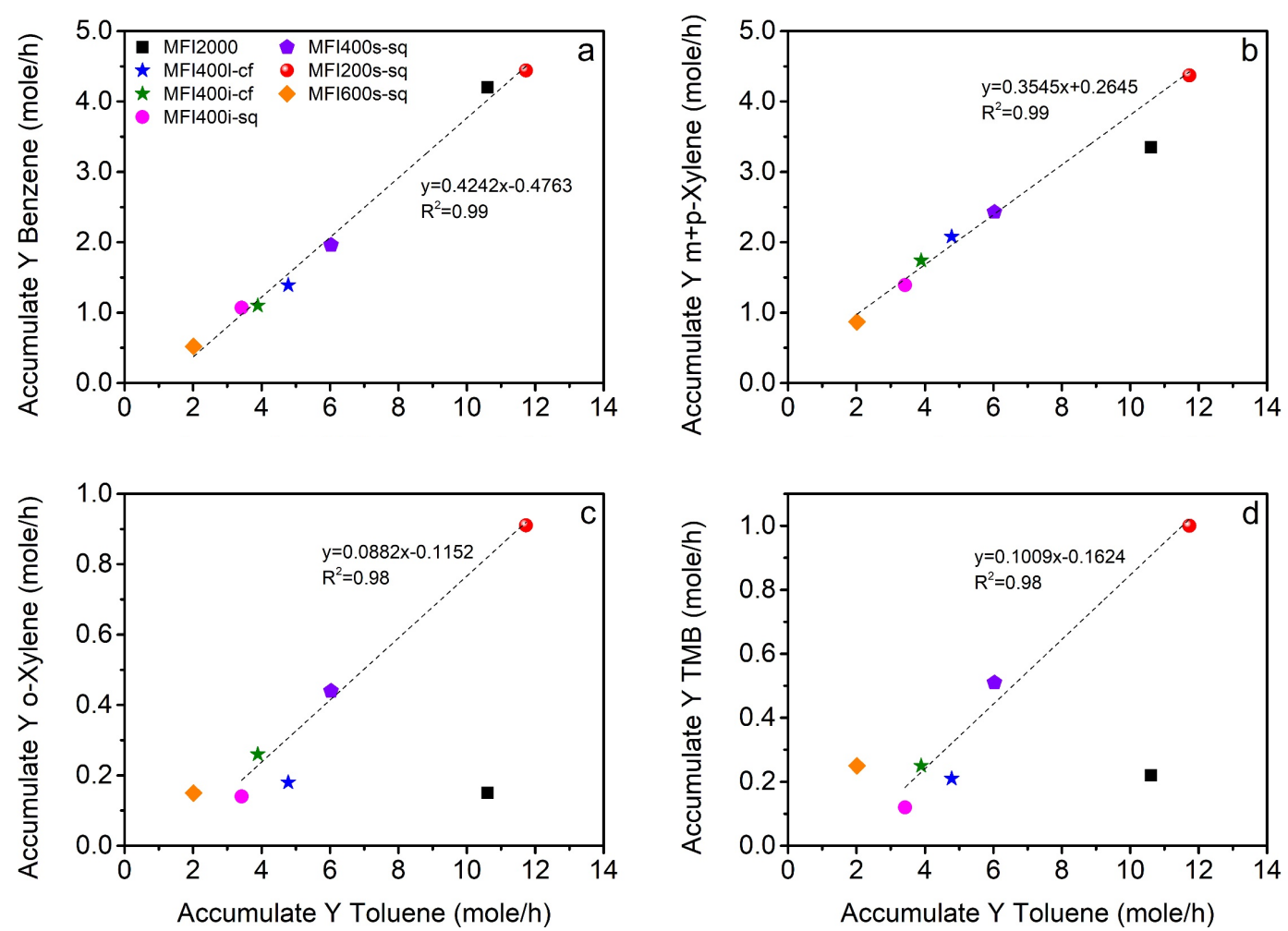

Figure 11. Accumulated yields of benzene (a), m+p-xylene (b), o-xylene (c) and TMB (d) as a function accumulated toluene yield for the different ZSM-5 catalysts. Accumulated yields obtained at TOS $=2 \mathrm{~h}$.

Along the whole work, it has been evidenced that all three catalyst descriptors affect the deactivation behaviour of the ZSM-5 zeolites in different degrees. Table S2 encloses the deactivation coefficients obtained by adjusting the activity vs TOS plots to a power law decay function ${ }^{80,81}$ and the deactivation coefficients per active Al site (see Figure S5 and Supporting Information, section S9 for more details). Figure S6 shows the correlation of the latter with crystal size for coffin and square-shaped morphology, with crystal 
morphology and with $\mathrm{Si} / \mathrm{Al}$ ratio for the small square-type ZSM-5, and the trends observed summarize the results discussed so far. Thus, deactivation constants decrease when reducing crystal size for both, coffin and square-shaped crystals, and are smaller for ZSM-5 with squared-type morphology than with coffin-type crystals when comparing intermediate-sized crystallites. The deactivation constant is higher for the coffin-type sample with intermediate size (MFI400i-cf) than for the large coffin-shaped sample (MFI4001-cf) and this is accordance to the abovementioned discussion. The former showed relative longer crystal length along $a$ (parallel to the sinusoidal channels) vs the crystal dimension along $b$ (parallel to the straight pores) and the sinusoidal channels tend to deactivate faster due to the formation of external surface coke. Finally, when comparing the small-squared-shaped ZSM-5 with different $\mathrm{Al}$ content, the variation in the decay constant increases when increasing the $\mathrm{Si} / \mathrm{Al}$ ratio. This unexpected behaviour can be explained by the low coking capacity of these small ZSM-5 crystals. Thus, reducing the $\mathrm{Al}$ content and, therefore, the amount of active sites, will only have a negative influence on initial activity and catalyst life under our conditions, and the larger amount of active sites in the sample with higher $\mathrm{Al}$ content will result in a higher stability of this catalyst with TOS.

\section{Conclusions}

A rationalized synthesis strategy has enabled unravelling the independent effect of crystal size, crystal morphology and $\mathrm{Si} / \mathrm{Al}$ ratio of different ZSM-5 based catalyst on the butenes cracking to propene. Thus, two sets of samples have been prepared under fluoride-free media, a first one with comparable $\mathrm{Si} / \mathrm{Al}$ ratio but different crystal size (lengths from 1 to $10 \mu \mathrm{m}$ ) and morphology (coffin vs. square-shaped crystals), and a second one where the 
$\mathrm{Si} / \mathrm{Al}$ ratio has been varied from 150 up to 600 for ZSM-5 samples with comparable square shaped crystallites with sizes below $1 \mu \mathrm{m}$.

According to the results obtained, an optimum ZSM-5 based catalyst for butenes cracking to propene should meet the following diffusional and compositional descriptors:

- Crystals with square-shaped morphology and $a /$ length- $c$, close to 1 are preferred over coffin type crystals for maximizing catalyst life. The larger diffusional limitations of the latter, caused by the presence crystal discontinuities (individual components, such as tips, intergrowths, interfaces) result in enhanced aromatization, preferentially following direct dehydrogenation routes, and faster catalyst deactivation.

- Small crystal ZSM-5, with sub-micron crystal dimensions along the $a$ and $b$ axis, parallel to the sinusoidal and straight channels, respectively, will enhance diffusion of the desired propene before it gets involved in undesired consecutive oligomerization reactions. Short dimension of the crystals along $c(\leq 1 \mu \mathrm{m})$ will reduce the number of channel intersections and, consequently, the probability of aromatics' formation.

- $\mathrm{Si} / \mathrm{Al}$ ratios around 300 have shown maximum propene yields. Reducing Al content penalizes the initial activity of the catalyst, as could be expected because of the lower amount of active sites, whereas reducing the $\mathrm{Si} / \mathrm{Al}$ ratio to values below 300 reduces propene selectivity in favour of aromatics.

Summarizing, this study presents the guidelines for increasing the efficiency of ZSM-5 based catalysts for butenes cracking to propene by properly adjusting crystal size, morphology and $\mathrm{Si} / \mathrm{Al}$ ratio of the zeolites. In contrast to the large ZSM-5 crystallites with very high $\mathrm{Si} / \mathrm{Al}$ ratios generally reported, the optimal catalyst in terms of catalyst activity, 
catalyst stability and propene selectivity was found to be a ZSM-5 zeolites with submicron sized crystals $(0.8 \times 0.3 \times 1 \mu \mathrm{m})$, square-shaped morphology, and $\mathrm{Si} / \mathrm{Al}$ ratio around 300.

\section{Supporting Information}

Supporting Information contains details on zeolite synthesis, characterization techniques and catalytic testing, and figures on evolution of butenes conversion with TOS at similar initial conversion, catalytic results obtained with silicalite ZSM-5, molar yields for the products distribution within the $\mathrm{C} 5+$ olefins, paraffins and aromatics and naphthenes fractions, as well as the fittings of activity curves to a deactivation function, the values obtained for the deactivation constants and their correlation with catalyst descriptors.

\section{Acknowledgements}

This work has been supported by Saudi Aramco and by the Spanish GovernmentMICINN through "Severo Ochoa” (SEV-2016-0683) and RTI2018-101033-B-I00. We thank the Electron Microscopy Service of the UPV for their help in sample characterization. 


\section{References}

(1) Agency, I. E. The Future of Petrochemicals: Towards More Sustainable Plastics and Fertilisers. IEA Publications France 2018, http://www.iea.org (Accessed February 2020).

(2) Sholl, D. S.; Lively, R. P. Seven Chemical Separations to Change the World. Nature 2016, 532 (7600), 435-437.

(3) Bereciartua, P. J.; Cantín, Á.; Corma, A.; Jordá, J. L.; Palomino, M.; Rey, F.; Valencia, S.; Corcoran, E. W.; Kortunov, P.; Ravikovitch, P. I. Control of Zeolite Framework Flexibility and Pore Topology for Separation of Ethane and Ethene. Science (80-. ). 2017, 358 (6366), 1068-1071.

(4) Jordá, J. L.; Rey, F.; Sastre, G.; Valencia, S.; Palomino, M.; Corma, A.; Segura, A.; Errandonea, D.; Lacomba, R.; Manjón, F. J. Synthesis of a Novel Zeolite through a Pressure-Induced Reconstructive Phase Transition Process. Angew. Chemie Int. Ed. 2013, 52 (40), 10458-10462.

(5) Gutiérrez-Sevillano, J. J.; Dubbeldam, D.; Rey, F.; Valencia, S.; Palomino, M.; Martín-Calvo, A.; Calero, S. Analysis of the ITQ-12 Zeolite Performance in Propane- Propene Separations Using a Combination of Experiments and Molecular Simulations. J. Phys. Chem. C 2010, 114 (35), 14907-14914.

(6) Palomino, M.; Cantín, A.; Corma, A.; Leiva, S.; Rey, F.; Valencia, S. Pure Silica ITQ-32 Zeolite Allows Separation of Linear Olefins from Paraffins. Chem. Commun. 2007, 12, 1233-1235.

(7) Blay, V.; Miguel, P. J.; Corma, A. Theta-1 Zeolite Catalyst for Increasing the Yield of Propene When Cracking Olefins and Its Potential Integration with an Olefin 
Metathesis Unit. Catal. Sci. Technol. 2017, 7, 5847-5859.

(8) Corma, A.; Corresa, E.; Mathieu, Y.; Sauvanaud, L.; Al-Bogami, S.; Al-Ghrami, M. S.; Bourane, A. Crude Oil to Chemicals: Light Olefins from Crude Oil. Catal. Sci. Technol. 2017, 7 (1), 12-46.

(9) Chen, J. Q.; Bozzano, A.; Glover, B.; Fuglerud, T.; Kvisle, S. Recent Advancements in Ethene and Propene Production Using the UOP/Hydro MTO Process. Catal. Today 2005, 106 (1-4), 103-107.

(10) Al-Khattaf, S. S.; Palani, A.; Bhuiyan, T. I.; Shaikh, S.; Akhtar, M. N.; Aitani, A. M.; Al-Yami, M. A. Dual Catalyst System for Propene Production 2018, US Patent US 10,052,618 B2.

(11) Alshafei, F. H.; Khokhar, M. D.; Sulais, N. A.; Alalouni, M. R.; Shaikh, S. K. Multiple-Stage Catalyst System for Self-Metathesis with Controlled Isomerization and Cracking 2018, US Patent US 2018/0208524 A1.

(12) Khokhar, M. D.; Alshafei, F. H.; Sulais, N. A.; Shaikh, S. K.; Abudawoud, R. H. Dual Catalyst Processes and Systems for Propene Production 2019, US Patent US $10,329,225 \mathrm{~B} 2$.

(13) Shaikh, S.; Jamal, A.; Zhang, Z. Systems and Methods for Producing Propene 2017, US Patent US 9,834,497 B2.

(14) Arudra, P.; Bhuiyan, T. I.; Akhtar, M. N.; Aitani, A. M.; Al-Khattaf, S. S.; Hattori, H. Silicalite-1 as Efficient Catalyst for Production of Propene from 1-Butene. ACS Catal. 2014, 4 (11), 4205-4214.

(15) Lin, L.; Qiu, C.; Zhuo, Z.; Zhang, D.; Zhao, S.; Wu, H.; Liu, Y.; He, M. Acid Strength Controlled Reaction Pathways for the Catalytic Cracking of 1-Butene to 
Propene over ZSM-5. J. Catal. 2014, 309, 136-145.

(16) Zhao, G.; Teng, J.; Xie, Z.; Jin, W.; Yang, W.; Chen, Q.; Tang, Y. Effect of Phosphorus on HZSM-5 Catalyst for C4-Olefin Cracking Reactions to Produce Propene. J. Catal. 2007, 248 (1), 29-37.

(17) Blay, V.; Epelde, E.; Miravalles, R.; Perea, L. A. Converting Olefins to Propene: Ethene to Propene and Olefin Cracking. Catal. Rev. 2018, 60(2) 278-335.

(18) Shi, J.; Wang, Y.; Yang, W.; Tang, Y.; Xie, Z. Recent Advances of Pore System Construction in Zeolite-Catalyzed Chemical Industry Processes. Chem. Soc. Rev. 2015, 44 (24), 8877-8903.

(19) Zhao, G.-L.; Teng, J.-W.; Xie, Z.-K.; Yang, W.-M.; Chen, Q.-L.; Tang, Y. Catalytic Cracking Reactions of C 4-Olefin over Zeolites H-ZSM-5, H-Mordenite and H-SAPO-34. Stud. Surf. Sci. Catal. 2007, 170, 1307-1312.

(20) Zhu, X.; Liu, S.; Song, Y.; Xu, L. Catalytic Cracking of C4 Alkenes to Propene and Ethene: Influences of Zeolites Pore Structures and Si/A1 2 Ratios. Appl. Catal. A Gen. 2005, 288 (1), 134-142.

(21) Xu, G.; Zhu, X.; Xie, S.; Li, X.; Liu, S.; Xu, L. 1-Butene Cracking to Propene on High Silica HMCM-22: Relations between Product Distribution and Feed Conversion under Various Temperatures. Catal. Letters 2009, 130 (1-2), 204-210.

(22) Zhu, X.; Liu, S.; Song, Y.; Xie, S.; Xu, L. Catalytic Cracking of 1-Butene to Propene and Ethene on MCM-22 Zeolite. Appl. Catal. A Gen. 2005, 290 (1), 191199.

(23) Zhao, G.; Teng, J.; Zhang, Y.; Xie, Z.; Yue, Y.; Chen, Q.; Tang, Y. Synthesis of ZSM-48 Zeolites and Their Catalytic Performance in C 4-Olefin Cracking 
Reactions. Appl. Catal. A Gen. 2006, 299, 167-174.

(24) Sazama, P.; Dědeček, J.; Gabova, V.; Wichterlova, B.; Spoto, G.; Bordiga, S. Effect of Aluminium Distribution in the Framework of ZSM-5 on Hydrocarbon Transformation. Cracking of 1-Butene. J. Catal. 2008, 254 (2), 180-189.

(25) Epelde, E.; Gayubo, A. G.; Olazar, M.; Bilbao, J.; Aguayo, A. T. Modified HZSM5 Zeolites for Intensifying Propene Production in the Transformation of 1-Butene. Chem. Eng. J. 2014, 251, 80-91.

(26) Ibáñez, M.; Epelde, E.; Aguayo, A. T.; Gayubo, A. G.; Bilbao, J.; Castaño, P. Selective Dealumination of HZSM-5 Zeolite Boosts Propene by Modifying 1Butene Cracking Pathway. Appl. Catal. A Gen. 2017, 543, 1-9.

(27) Epelde, E.; Gayubo, A. G.; Olazar, M.; Bilbao, J.; Aguayo, A. T. Intensifying Propene Production by 1-Butene Transformation on a K Modified HZSM-5 Zeolite-Catalyst. Ind. Eng. Chem. Res. 2014, 53 (12), 4614-4622.

(28) Epelde, E.; Santos, J. I.; Florian, P.; Aguayo, A. T.; Gayubo, A. G.; Bilbao, J.; Castaño, P. Controlling Coke Deactivation and Cracking Selectivity of MFI Zeolite by H3PO4 or KOH Modification. Appl. Catal. A Gen. 2015, 505, 105-115.

(29) Xu, R.; Liu, J.; Liang, C.; Jia, W.; Li, F.; Guo, H. Effect of Alkali Metal Ion Modification on the Catalytic Performance of Nano-HZSM-5 Zeolite in Butene Cracking. J. Fuel Chem. Technol. 2011, 39 (6), 449-454.

(30) Zhu, X.; Liu, S.; Song, Y.; Xu, L. Butene Catalytic Cracking to Propene and Ethene over Potassium Modified ZSM-5 Catalysts. Catal. Letters 2005, 103 (3-4), 201210.

(31) Blasco, T.; Corma, A.; Martínez-Triguero, J. Hydrothermal Stabilization of ZSM- 
5 Catalytic-Cracking Additives by Phosphorus Addition. J. Catal. 2006, 237 (2), $267-277$.

(32) Lv, J.; Hua, Z.; Ge, T.; Zhou, J.; Zhou, J.; Liu, Z.; Guo, H.; Shi, J. Phosphorus Modified Hierarchically Structured ZSM-5 Zeolites for Enhanced Hydrothermal Stability and Intensified Propene Production from 1-Butene Cracking. Microporous Mesoporous Mater. 2017, 247, 31-37.

(33) Wang, Z.; Jiang, G.; Zhao, Z.; Feng, X.; Duan, A.; Liu, J.; Xu, C.; Gao, J. Highly Efficient P-Modified HZSM-5 Catalyst for the Coupling Transformation of Methanol and 1-Butene to Propene. Energy \& Fuels 2010, 24 (2), 758-763.

(34) Xue, N.; Chen, X.; Nie, L.; Guo, X.; Ding, W.; Chen, Y.; Gu, M.; Xie, Z. Understanding the Enhancement of Catalytic Performance for Olefin Cracking: Hydrothermally Stable Acids in P/HZSM-5. J. Catal. 2007, 248 (1), 20-28.

(35) Li, C.; Vidal-Moya, A.; Miguel, P. J.; Dedecek, J.; Boronat, M.; Corma, A. Selective Introduction of Acid Sites in Different Confined Positions in ZSM-5 and Its Catalytic Implications. ACS Catal. 2018, 8 (8), 7688-7697.

(36) Gao, X.; Tang, Z.; Lu, G.; Cao, G.; Li, D.; Tan, Z. Butene Catalytic Cracking to Ethene and Propene on Mesoporous ZSM-5 by Desilication. Solid State Sci. 2010, $12(7), 1278-1282$.

(37) Mitchell, S.; Boltz, M.; Liu, J.; Pérez-Ramírez, J. Engineering of ZSM-5 Zeolite Crystals for Enhanced Lifetime in the Production of Light Olefins via 2-Methyl-2Butene Cracking. Catal. Sci. Technol. 2017, 7 (1), 64-74.

(38) Shi, J.; Zhao, G.; Teng, J.; Wang, Y.; Xie, Z. Morphology Control of ZSM-5 Zeolites and Their Application in Cracking Reaction of C4 Olefin. Inorg. Chem. 
Front. 2018, 5 (11), 2734-2738.

(39) Al-Khattaf, S. S.; Palani, A.; Aitani, A. M. Catalytic Hydrocracking of Light Olefins 2017, US Patent US 9,783,464 B2.

(40) Johnson, D. L.; Nariman, K. E.; Ware, R. A. Catalytic Production of Light Olefins Rich in Propene 2001, US Patent US 6,222,087 B1.

(41) Wang, C.; Zhang, L.; Huang, X.; Zhu, Y.; Li, G. (Kevin); Gu, Q.; Chen, J.; Ma, L.; Li, X.; He, Q.; Xu, J.; Sun, Q.; Song, C.; Peng, M.; Sun, J.; Ma, D. Maximizing Sinusoidal Channels of HZSM-5 for High Shape-Selectivity to p-Xylene. Nat. Commun. 2019, 10 (1), 4348.

(42) Fu, D.; van der Heijden, O.; Stanciakova, K.; Schmidt, J. E.; Weckhuysen, B. M. Disentangling Reaction Processes of Zeolites within Single-Oriented Channels. Angew. Chemie Int. Ed. 2020, 59, 1-6.

(43) Xomeritakis, G.; Tsapatsis, M. Permeation of Aromatic Isomer Vapors through Oriented MFI-Type Membranes Made by Secondary Growth. Chem. Mater. 1999, $11(4), 875-878$.

(44) Bressel, A.; Donauer, T.; Sealy, S.; Traa, Y. Influence of Aluminum Content, Crystallinity and Crystallite Size of Zeolite Pd/H-ZSM-5 on the Catalytic Performance in the Dehydroalkylation of Toluene with Ethane. Microporous Mesoporous Mater. 2008, 109 (1-3), 278-286.

(45) Van der Pol, A.; Van Hooff, J. H. C. Parameters Affecting the Synthesis of Titanium Silicalite 1. Appl. Catal. A Gen. 1992, 92 (2), 93-111.

(46) Tang, X.; Zhou, H.; Qian, W.; Wang, D.; Jin, Y.; Wei, F. High Selectivity Production of Propene from N-Butene: Thermodynamic and Experimental Study 
Using a Shape Selective Zeolite Catalyst. Catal. Letters 2008, 125 (3-4), 380-385.

(47) Kokotailo, G. T.; Lawton, S. L.; Olson, D. H.; Meier, W. M. Structure of Synthetic Zeolite ZSM-5. Nature 1978, 272 (5652), 437-438.

(48) Rouquerol, J.; Llewellyn, P.; Rouquerol, F. Is the BET Equation Applicable to Microporous Adsorbents. Stud. Surf. Sci. Catal 2007, 160 (07), 49-56.

(49) Bonilla, G.; Díaz, I.; Tsapatsis, M.; Jeong, H.-K.; Lee, Y.; Vlachos, D. G. Zeolite (MFI) Crystal Morphology Control Using Organic Structure-Directing Agents. Chem. Mater. 2004, 16 (26), 5697-5705.

(50) Zhang, X.; Liu, D.; Xu, D.; Asahina, S.; Cychosz, K. A.; Agrawal, K. V.; Al Wahedi, Y.; Bhan, A.; Al Hashimi, S.; Terasaki, O. Synthesis of Self-Pillared Zeolite Nanosheets by Repetitive Branching. Science 2012, 336 (6089), 16841687.

(51) Choi, M.; Na, K.; Kim, J.; Sakamoto, Y.; Terasaki, O.; Ryoo, R. Stable SingleUnit-Cell Nanosheets of Zeolite MFI as Active and Long-Lived Catalysts. Nature 2009, 461 (7261), 246-249.

(52) Kox, M. H. F.; Stavitski, E.; Weckhuysen, B. M. Nonuniform Catalytic Behavior of Zeolite Crystals as Revealed by in Situ Optical Microspectroscopy. Angew. Chemie Int. Ed. 2007, 46 (20), 3652-3655.

(53) Roeffaers, M. B. J.; Ameloot, R.; Baruah, M.; Uji-i, H.; Bulut, M.; De Cremer, G.; Müller, U.; Jacobs, P. A.; Hofkens, J.; Sels, B. F. Morphology of Large ZSM-5 Crystals Unraveled by Fluorescence Microscopy. J. Am. Chem. Soc. 2008, 130 (17), 5763-5772.

(54) Roeffaers, M. B. J.; Ameloot, R.; Bons, A.-J.; Mortier, W.; De Cremer, G.; de 
Kloe, R.; Hofkens, J.; De Vos, D. E.; Sels, B. F. Relating Pore Structure to Activity at the Subcrystal Level for ZSM-5: An Electron Backscattering Diffraction and Fluorescence Microscopy Study. J. Am. Chem. Soc. 2008, 130 (41), 13516-13517.

(55) Koegler, J. H.; Van Bekkum, H.; Jansen, J. C. Growth Model of Oriented Crystals of Zeolite Si-ZSM-5. Zeolites 1997, 19 (4), 262-269.

(56) Treps, L.; Gomez, A.; De Bruin, T.; Chizallet, C. Environment, Stability and Acidity of External Surface Sites of Silicalite-1 and ZSM-5 Micro-and NanoSlabs,-Sheets and-Crystals. ACS Catal. 2020, 10 (5), 3297-3312.

(57) Zeng, G.; Chen, C.; Li, D.; Hou, B.; Sun, Y. Exposure of (001) Planes and (011) Planes in MFI Zeolite. CrystEngComm 2013, 15 (18), 3521-3524.

(58) Roeffaers, M. B. J.; Sels, B. F.; Uji-i, H.; Blanpain, B.; L’hoëst, P.; Jacobs, P. A.; De Schryver, F. C.; Hofkens, J.; De Vos, D. E. Space-and Time-resolved Visualization of Acid Catalysis in ZSM-5 Crystals by Fluorescence Microscopy. Angew. Chemie Int. Ed. 2007, 46 (10), 1706-1709.

(59) Díaz, I.; Kokkoli, E.; Terasaki, O.; Tsapatsis, M. Surface Structure of Zeolite (MFI) Crystals. Chem. Mater. 2004, 16 (25), 5226-5232.

(60) Lei, X.; Jockusch, S.; Ottaviani, M. F.; Turro, N. J. In Situ EPR Investigation of the Addition of Persistent Benzyl Radicals to Acrylates on ZSM-5 Zeolites. Direct Spectroscopic Detection of the Initial Steps in a Supramolecular Photopolymerization. Photochem. Photobiol. Sci. 2003, 2 (11), 1095-1100.

(61) Liu, C.; Kong, D.; Guo, H. The Morphology Control of Zeolite ZSM-5 by Regulating the Polymerization Degree of Silicon and Aluminum Sources. Microporous Mesoporous Mater. 2014, 193, 61-68. 
(62) Zhang, F.-Z.; Fuji, M.; Takahashi, M. In Situ Growth of Continuous B-Oriented MFI Zeolite Membranes on Porous $\alpha$-Alumina Substrates Precoated with a Mesoporous Silica Sublayer. Chem. Mater. 2005, 17 (5), 1167-1173.

(63) Corma, A.; Orchillés, A. V. Current Views on the Mechanism of Catalytic Cracking. Microporous Mesoporous Mater. 2000, 35-36, 21-30.

(64) Corma, A.; Miguel, P. J.; Orchilles, A. V. The Role of Reaction Temperature and Cracking Catalyst Characteristics in Determining the Relative Rates of Protolytic Cracking, Chain Propagation, and Hydrogen Transfer. J. Catal. 1994, 145 (1), $171-180$.

(65) Corma, A.; Miguel, P. J.; Orchilles, A. V; Koermer, G. Zeolite Effects on the Cracking of Long Chain Alkyl Aromatics. J. Catal. 1994, 145 (1), 181-186.

(66) Li, J.; Li, T.; Ma, H.; Sun, Q.; Li, C.; Ying, W.; Fang, D. Kinetics of Coupling Cracking of Butene and Pentene on Modified HZSM-5 Catalyst. Chem. Eng. J. 2018, 346, 397-405.

(67) Ma, Y.; Cai, D.; Li, Y.; Wang, N.; Muhammad, U.; Carlsson, A.; Tang, D.; Qian, W.; Wang, Y.; Su, D. The Influence of Straight Pore Blockage on the Selectivity of Methanol to Aromatics in Nanosized Zn/ZSM-5: An Atomic Cs-Corrected STEM Analysis Study. RSC Adv. 2016, 6 (78), 74797-74801.

(68) Wang, N.; Sun, W.; Hou, Y.; Ge, B.; Hu, L.; Nie, J.; Qian, W.; Wei, F. CrystalPlane Effects of MFI Zeolite in Catalytic Conversion of Methanol to Hydrocarbons. J. Catal. 2018, 360, 89-96.

(69) Sarazen, M. L.; Doskocil, E.; Iglesia, E. Effects of Void Environment and Acid Strength on Alkene Oligomerization Selectivity. ACS Catal. 2016, 6 (10), 7059- 
7070.

(70) Abdalla, A.; Arudra, P.; Al-Khattaf, S. S. Catalytic Cracking of 1-Butene to Propene Using Modified H-ZSM-5 Catalyst: A Comparative Study of Surface Modification and Core-Shell Synthesis. Appl. Catal. A Gen. 2017, 533, 109-120.

(71) Bortnovsky, O.; Sazama, P.; Wichterlova, B. Cracking of Pentenes to C2-C4 Light Olefins over Zeolites and Zeotypes: Role of Topology and Acid Site Strength and Concentration. Appl. Catal. A Gen. 2005, 287 (2), 203-213.

(72) Gobin, O. C.; Reitmeier, S. J.; Jentys, A.; Lercher, J. A. Comparison of the Transport of Aromatic Compounds in Small and Large MFI Particles. J. Phys. Chem. C 2009, 113 (47), 20435-20444.

(73) Gobin, O. C.; Reitmeier, S. J.; Jentys, A.; Lercher, J. A. Diffusion Pathways of Benzene, Toluene and p-Xylene in MFI. Microporous Mesoporous Mater. 2009, $125(1-2), 3-10$.

(74) Derouane, E. G.; Gabelica, Z. Novel Effect of Shape Selectivity Molecular Traffic Control in Zeolite ZSM-5. J. Catal 1980, 65 (2), 486.

(75) Iwase, Y.; Sakamoto, Y.; Shiga, A.; Miyaji, A.; Motokura, K.; Koyama, T.; Baba, T. Shape-Selective Catalysis Determined by the Volume of a Zeolite Cavity and the Reaction Mechanism for Propene Production by the Conversion of Butene Using a Proton-Exchanged Zeolite. J. Phys. Chem. C 2012, 116 (8), 5182-5196.

(76) Ono, Y.; Kitagawa, H.; Sendoda, Y. Transformation of But-1-Ene into Aromatic Hydrocarbons over ZSM-5 Zeolites. J. Chem. Soc. Faraday Trans. 1 Phys. Chem. Condens. Phases 1987, 83 (9), 2913-2923.

(77) Coelho, A.; Caeiro, G.; Lemos, M. A. N. D. A.; Lemos, F.; Ribeiro, F. R. 1-Butene 
Oligomerization over ZSM-5 Zeolite: Part 1 - Effect of Reaction Conditions. Fuel 2013, 111, 449-460.

(78) Aloise, A.; Catizzone, E.; Migliori, M.; B.Nagy, J.; Giordano, G. Catalytic Behavior in Propane Aromatization Using GA-MFI Catalyst. Chinese J. Chem. Eng. 2017, 25 (12), 1863-1870.

(79) Song, L.; Rees, L. V. C. Adsorption and Diffusion of Cyclic Hydrocarbon in MFIType Zeolites Studied by Gravimetric and Frequency-Response Techniques. Microporous Mesoporous Mater. 2000, 35, 301-314.

(80) Voorhies Jr, A. Carbon Formation in Catalytic Cracking. Ind. Eng. Chem. 1945, $37(4), 318-322$.

(81) Fogler, H. S. Elements of Chemical Reaction Engineering. Prentice Hall Profesional, United States 2006, Chapter 10, Section 10.7, 717. 